This item was submitted to Loughborough's Research Repository by the author.

Items in Figshare are protected by copyright, with all rights reserved, unless otherwise indicated.

\title{
Optimal retirement with borrowing constraints and forced unemployment risk
}

PLEASE CITE THE PUBLISHED VERSION

https://doi.org/10.1016/j.insmatheco.2020.06.002

PUBLISHER

Elsevier

VERSION

AM (Accepted Manuscript)

PUBLISHER STATEMENT

This paper was accepted for publication in the journal Insurance: Mathematics and Economics and the definitive published version is available at https://doi.org/10.1016/j.insmatheco.2020.06.002.

\section{LICENCE}

CC BY-NC-ND 4.0

\section{REPOSITORY RECORD}

Jang, Bong-Gyu, Seyoung Park, and Huainan Zhao. 2020. "Optimal Retirement with Borrowing Constraints and Forced Unemployment Risk”. Loughborough University. https://hdl.handle.net/2134/12687878.v1. 


\title{
Optimal Retirement with Borrowing Constraints and Forced Unemployment Risk*
}

\author{
Bong-Gyu Jang ${ }^{\dagger}$, Seyoung Park ${ }^{\ddagger}$, and Huainan Zhao ${ }^{\$}$
}

${ }^{\dagger}$ Department of Industrial and Management Engineering, POSTECH, Korea. E-mail: bonggyujang@postech.ac.kr

${ }^{\ddagger}$ Corresponding Author: Nottingham University Business School, University of Nottingham, Jubilee Cam-

pus, Nottingham, NG8 1BB, UK, Tel: +44-7927-494518, E-mail: seyoung.park@nottingham.ac.uk

\$ School of Business and Economics, Loughborough University, UK. E-mail: H.Zhao6@lboro.ac.uk

${ }^{*}$ We would like to thank Amy Ward, Emanuele Borgonovo, Min Dai, Steven Kou, Hong Liu, Eckhard

Platen, Giuseppe Moscarini, Ricardo Lagos, Carol Alexander, Alain Bensoussan, Ales Cerny, Hyeng Keun

Koo, Bong Soo Lee, Xuezhong He, Shanjian Tang, Young Ho Eom, Jaehoon Hahn, Yong Hyun Shin, Jane Yoo, and the seminar participants at the 9th International Conference on Asia-Pacific Financial Markets, the Quantitative Methods in Finance 2016 Conference, Korea University Business School and Yonsei University Business School for helpful comments. This article is a revised version of Chapter 3 of Seyoung Park's Ph.D. dissertation submitted to the Department of Industrial and Management Engineering, POSTECH. The research of this paper was supported by the Ministry of Education of the Republic of Korea and the National Research Foundation of Korea (NRF-2019S1A5A2A03054249). 


\title{
Optimal Retirement with Borrowing Constraints and Forced Unemployment Risk*
}

\begin{abstract}
In this paper, we study optimal retirement in a two-dimensional incomplete market caused by borrowing constraints and forced unemployment risk. We show that the two aspects jointly affect an individual's optimal consumption, investment, and retirement strategies. In contrast to the complete market case, the endogenously determined wealth threshold for retirement is significantly affected by the two-dimensional market incompleteness, resulting in a lower wealth threshold. We also discuss a possible unemployment insurance scheme for the borrowing-constrained individual to respond to the shocks of forced unemployment.
\end{abstract}

Keywords: Optimal Retirement, Forced Unemployment Risk, Borrowing Constraints, Dynamic Programming

JEL Classifications: C61, E21, G11 


\section{Introduction}

Bensoussan, Jang, and Park (2016), hereafter BJP, develop a model of optimal retirement that deals with both income risks and endogenous (voluntary) retirement in an incomplete market, ${ }^{1}$ where the risk of forced unemployment is unhedgeable. BJP's work is the first attempt to solve the incomplete-market retirement problem with the risk of forced unemployment, since prior studies either do not account for the forced unemployment risk (Dybvig and Liu, 2010) or assume market completeness with hedgeable risk (Farhi and Panageas, 2007; Jang et al., 2013). The BJP model, however, faces a major limitation by neglecting one significant dimension of market incompleteness: the borrowing constraints against human capital. ${ }^{2}$

Borrowing against human capital (i.e., the present value of one's future income) plays a vital role in household investment and savings decisions, since total available financial resources for investment and consumption are expanded by the opportunity of borrowing (Merton, 1969, 1971). In the actual credit market, however, the individual's ability to borrow is constrained by market frictions such as asymmetric information, agency conflicts, and limited enforcement. According to the Survey of Consumer Finances (2017), "In 2016,

\footnotetext{
${ }^{1}$ The individual's optimal retirement decision is to exchange the value of labor income with the extra leisure that is brought about by exiting the workforce permanently at any time she determines, which resembles an optimal stopping decision.

${ }^{2}$ Prior studies have considered the joint effects of labor income risk and borrowing constraints on the lifetime consumption and investment strategies in the absence of endogenous (or voluntary) retirement. For instance, Carroll (1992), Cocco et al. (2005), Polkovnichenko (2007), Munk and Sørensen (2010), Lynch and Tan (2011), Wang et al. (2016), and Ahn et al. (2019).
} 
20.8 percent of families were considered credit constrained - those who reported being denied credit in the past year, as well as those who did not apply for credit for fear of being denied in the past year." Borrowing constraint is, thus, a significant dimension of market incompleteness.

Prior work on life-cycle models with endogenous (or voluntary) retirement opportunity studies the effects of borrowing constraints against future labor income on the optimal consumption and investment strategies. For instance, Farhi and Panageas (2007) and Dybvig and Liu (2010) show that retirement flexibility and borrowing constraints are leading factors in determining optimal consumption and investment strategies over the life cycle. However, their models have overlooked the risk of forced unemployment. It is, thus, unclear what a model of optimal retirement with the two-dimensional market incompleteness (i.e., borrowing constraints and forced unemployment risk) can deliver.

Household life-cycle decisions are further complicated by the rapid developments in artificial intelligence (AI) and automation, which significantly disrupt labor markets, and hence, raise the risk of forced unemployment. ${ }^{3}$ Thus, labor market challenges combined with capital market frictions (borrowing constraints) hinder the individual's ability to derive successful life-cycle strategies. Recent evidence points out that many households are prone to unexpected hardship and struggling with how to continue being able to afford what they can currently afford (Federal Reserve report, 2017; European Commission statistics,

\footnotetext{
${ }^{3}$ Frey and Osborne (2017) show that around $50 \%$ of U.S. jobs performed by the human can be replaced by automation with AI.
} 
2017). ${ }^{4}$ In this paper, we attempt to address the earnings insecurity and volatility towards the end of the human life cycle by analyzing the optimal consumption, investment, and retirement decisions of an utility-maximizing individual encountering a two-dimensional market incompleteness (borrowing constraints and forced unemployment risk).

One of the main difficulties of our analysis lies in that allowing for an extra dimension of risk or a constraint in financial markets gives rise to considerable challenges in solving the problems. Adding borrowing constraints makes the derivations and verification of optimal strategies particularly difficult (Dybvig and Liu, 2011). Existing convex-duality approaches of Cox and Huang (1989), Karatzas et al. (1991), Karatzas and Wang (2000), Dybvig and Liu (2011), Jang et al. (2013), and BJP are incapable of solving our retirement problem with the two-dimensional market incompleteness. In particular, the methods of Cox and Huang (1989), Karatzas and Wang (2000), Dybvig and Liu (2011), and Jang et al. (2013) rely on the complete market assumption. Although the method of Karatzas et al. (1991) can be applied to problems in an incomplete market, it is unable to account for jump-type income risk by considering only standard Brownian motions. The method of BJP is limited by relying on a piecewise connected utility function to guarantee the boundedness of the marginal value function.

In our study, we overcome these limitations and solve the optimal retirement model in

\footnotetext{
${ }^{4} 44 \%$ of U.S. households are not ready to cover emergency expenses of merely $\$ 400$ ("Report on the Economic Well-Being of U.S. Households in 2016" published by Board of Governors of the Federal Reserve System on May 2017) and about 218 million E.U. households are less likely to be able to fund their future consumption needs (EU Statistics on Income and Living Conditions, EU-SILC 2017).
} 
an incomplete market. Specifically, we develop a new dynamic programming approach to solve the optimal retirement model in the two-dimensional incomplete market (with borrowing constraints and forced unemployment risk). ${ }^{5}$ We generalize BJP's framework with a logarithmic utility function as usual, irrespective of its piecewise connectivity assumed in BJP. ${ }^{6}$ We provide a general solution to the nonlinear differential equation with two free boundaries, and verify its existence and uniqueness. ${ }^{7}$ We also devise a simple numerical algorithm for graphical illustrations of optimal strategies. To the best of our knowledge, ours is the first study to analytically derive and theoretically verify the optimal consumption, investment, and retirement strategies within the two-dimensional market incompleteness

\footnotetext{
${ }^{5}$ The other approach for solving an optimal retirement model is to use the principle of dynamic programming. Specifically, one needs to solve variational inequalities when applying dynamic programming to the retirement problem. The optimal retirement models in complete markets have been solved by the dynamic programming approach, where the resulting linear differential equation with a free (or an optimal stopping) boundary can be solved analytically. However, when markets are incomplete, there exists undiversifiable risks, resulting in great complexity in the differential equation. The key issue is the market incompleteness that results in highly nonlinear terms in the differential equation, which is almost impossible to be solved analytically or even numerically.

${ }^{6}$ BJP provides a useful base for understanding the one-dimensional market incompleteness by focusing on the forced unemployment risk. The two-dimensional incomplete market framework with the logarithmic utility function allows us to draw important quantitative implications of market incompleteness in the simplest possible setting. The general case with power utility or stochastic differential utility might not admit a closed-form solution as in the logarithmic case. One may develop an asymptotic expansion to solve such a general case.

${ }^{7}$ The verification theorems of existence and uniqueness can be readily applied to other incomplete market problems. This is one of our technical contributions.
} 
framework.

We show that borrowing constraints and forced unemployment risk jointly affect an individual's optimal consumption, investment, and retirement strategies. Specifically, we find that, under the two-dimensional market incompleteness, the individual's excess hedging demand leads to excess wealth accumulation. ${ }^{8}$ Such an increased need for hedging can be characterized by two opposing effects on the individual's investment decisions. On the one hand, the market incompleteness increases the background risk, driving the precautionary savings motive that reduces risky investment (Campbell, 1987; Kimball, 1993). On the other hand, it encourages the diversification motive that increases risky investment (Benzoni et al., 2007; Ahn et al., 2019). While the optimal decision to increase or decrease risky investment depends on one's financial wealth and investment opportunities.

Notably, we find that there exists a certain endogenously determined wealth threshold over which it is optimal for the individual to enter voluntary retirement (e.g., Farhi and Panageas 2007; Dybvig and Liu, 2010; Jang et al., 2013). In contrast to the complete market case, the endogenously determined wealth threshold for retirement is significantly affected by the two-dimensional market incompleteness, resulting in a lower wealth threshold. Thus, neglecting market incompleteness can be costly to the borrowing-constrained individual who aims to attain her optimal retirement. We calculate the resulting utility

\footnotetext{
${ }^{8}$ An individual's hedging demand induced by the diversification motive results from two sources: the stock market risk and the forced unemployment risk. The effectiveness of hedging depends on the amount of available financial wealth for future consumption, so the individual has an incentive to accumulate her wealth.
} 
costs of ignoring the market incompleteness. The individual could lose up to $10 \%$ of her retirement wealth if she does not consider market incompleteness. ${ }^{9}$

We also discuss a possible unemployment insurance scheme (as a pre-arranged financing instrument) for the borrowing-constrained individual to respond to or recover from the shocks of forced unemployment. Specifically, we consider two opposing scenarios. On the one hand, the individual can adopt the unemployment insurance in the complete market as in Jang et al. (2013). On the other hand, she can still manage her income shocks even if the insurance contract is not available, as outlined in our incomplete market framework. By comparing the value functions of the two opposing scenarios (with and without the unemployment insurance), we calculate a fair value of the unemployment insurance. The fair value, we hope, will serve as a starting point towards designing such a new insurance contract.

The paper is organized as follows. In Section 2, we develop an optimal retirement model in a two-dimensional incomplete market, which is caused by forced unemployment risk and borrowing constraints. In Section 3, we solve the retirement model and provide analytic results for optimal strategies. In Section 4, we conduct a quantitative analysis to illustrate various properties of optimal strategies. In Section 5, we conclude the paper.

\footnotetext{
${ }^{9}$ The result of our cost analysis when neglecting the market incompleteness is in line with the difficulty of addressing the high costs associated with youth unemployment. As Center for American Progress states, "Building on this research, we estimate that the nearly 1 million young Americans who experienced longterm unemployment during the worst of the recession will lose more than 20 billion in earnings over the next 10 years. This equates to about 22,000 per person. The economic consequences of these lost wages to individuals and to the broader economy are serious." (Center for American Progress April 5, 2013)
} 


\section{The Model}

\subsection{Utility Function}

An individual has the following logarithmic and time-additive utility function of CobbDouglas type (BJP):

$$
U(l(t), c(t)) \equiv \frac{1}{a} \ln \left(l(t)^{1-a} c(t)^{a}\right)
$$

where $c(t)$ is per-period consumption, $l(t)$ is leisure preference at time $t$, and $0<a<1$ is the weight for consumption. We assume that the individual enjoys leisure $l(t)=\underline{l}$ while in employment and $l(t)=\bar{l}(\bar{l} \geq \underline{l}>0)$ when she retires. ${ }^{10}$ If we normalize pre-retirement leisure $\underline{l}$ as 1 , the utility function during employment is given by

$$
U(1, c(t))=\ln c(t)
$$

The utility function after (voluntary or involuntary) retirement is

$$
U(\bar{l}, c(t))=\ln \left\{\bar{l}^{1 / a-1} c(t)\right\}
$$

For notational simplicity, we introduce a constant $K$ :

$$
K \equiv \bar{l}^{1 / a-1}>1
$$

\footnotetext{
${ }^{10}$ In this paper, labor supply can be adjusted only through the decision of optimal retirement timing. This is known as the labor supply flexibility along the extensive margin. If individuals can adjust hours of work on the job (Bodie et al., 1992), i.e., when the labor supply along the intensive margin is considered, some results might be modified qualitatively or quantitatively. To obtain an analytically tractable life-cycle model, we follow Farhi and Panageas (2007) and Dybvig and Liu (2010) who assume that the individual's labor supply is flexibly controlled by her optimal timing of retirement (rather than by adjusting working hours).
} 
The constant represents post-retirement leisure preference, i.e., the individual enjoys more leisure as $K$ increases. ${ }^{11}$

\subsection{Financial Market}

Following the conventional life-cycle models (Merton, 1969, 1971), we assume that there are two tradable assets in the financial market: a riskless bond and a risky stock. ${ }^{12}$ The bond price $B(t)$ follows

$$
d B(t)=r B(t) d t
$$

where $r(r>0)$ is the risk-free interest rate. The stock price $S(t)$ is given by the following geometric Brownian motion:

$$
d S(t)=\mu S(t) d t+\sigma S(t) d W(t)
$$

where $\mu(\mu>r)$ is the expected rate of stock return, $\sigma(\sigma>0)$ is the volatility of the return, and $W(t)$ is a standard one-dimensional Brownian motion defined on a filtered probability space $\left(\Omega, \mathcal{F},\left\{\mathcal{F}_{t}\right\}, P\right) .{ }^{13}$ The investment opportunity provided by the stock is

\footnotetext{
${ }^{11}$ The constant $K$ also reflects the fact that the marginal utility of consumption is larger after retirement than before retirement. This preference for leisure after retirement results from a disutility of work, or household production, or cost savings (Dybvig and Liu, 2010). For instance, retirement may allow sufficient time to enjoy leisure, spent away from business work, domestic chores, and education.

${ }^{12}$ The single risky asset assumption can be relaxed to allow for multiple risky assets, but it will not alter our main results.

${ }^{13}$ All stochastic processes are assumed to be adapted to $\left\{\mathcal{F}_{t}\right\}_{t \geq 0}$, which is the $P$-augmentation of the filtration driven by the Brownian motion. Throughout the paper, all stated processes are assumed to be well defined without explicitly stating the usual conditions guaranteeing this.
} 
characterized by its risk premium $\mu-r$ and volatility $\sigma$, which are assumed to be constant, i.e., $\mu, r, \sigma$ are positive constants. ${ }^{14}$

\subsection{Forced Unemployment Risk}

In the absence of forced unemployment risk, the individual with no retirement opportunity works full time permanently with labor income $I_{1}$, which is certain and insurable over the life-cycle. In this case, the individual has the following present value of future income discounted by the risk-free interest rate $r$ (Friedman, 1957):

$$
E\left[\int_{0}^{\infty} e^{-r t} I_{1} d t\right]=\frac{I_{1}}{r},
$$

which represents the individual's expected human wealth. ${ }^{15}$

\footnotetext{
${ }^{14}$ The assumption of a geometric Brownian motion for the stock price, combined with that the investment opportunity is constant, is standard in the literature on life-cycle consumption and portfolio choice (Farhi and Panageas, 2007; Dybvig and Liu, 2010; Jang et al., 2013; Bensoussan, Jang, and Park, 2016).

${ }^{15}$ If we consider mortality risk modeled by a Poisson shock with intensity $\nu>0$, the present value of future income discounted by the risk-free interest rate $r$ is$$
E\left[\int_{0}^{\tau_{M}} e^{-r t} I_{1} d t\right]=\frac{I_{1}}{r+\nu}
$$

where $\tau_{M}$ represents the individual's death time, when the value of income jumps to zero. The effects of mortality risk replace the discount rate of $r$ by $r+\nu$, which does not alter the qualitative features of the present value of future income. Throughout the paper, the risk-free interest rate $r$ can be thought of as the constant discount factor incorporating the constant hazard rate $\nu$ of death. The present value of future income would be changed both qualitatively and quantitatively if we allowed for a highly nonlinear hazard into death by introducing an extra stochastic process for time-varying $\nu$, which is beyond the paper's current scope and left for future research.
} 
Following BJP, the individual with a retirement opportunity either works full time with an annual income $I_{1}$ or enters (voluntary or involuntary) retirement with an annual income $I_{2}\left(I_{1}>I_{2}\right) .{ }^{16}$ In the presence of forced unemployment risk, the individual encounters an unexpected, exogenous, and permanent reduction in labor income from $I_{1}$ to $I_{2} \cdot{ }^{17}$ To include a disastrous labor income shock caused by forced unemployment, we allow for a very small probability of a severe downward jump in the individual's labor income process. The individual could lose her job when an exogenous permanent unemployment shock occurs, which is distributed according to an exponential distribution with positive intensity $\delta$. More specifically, for time $t \geq 0$

$$
\text { Probability of }\left\{\tau_{U} \leq t\right\}=1-e^{-\delta t}
$$

where $\tau_{U}$ is the time at which forced unemployment occurs. ${ }^{18}$ Thus, the individual works

\footnotetext{
${ }^{16}$ Economists usually assume that the income rate of $I_{1}$ is equivalent to $\omega(\bar{l}-\underline{l})$ during employment, if the wage rate $\omega>0$ is constant.

${ }^{17}$ Theoretical and empirical work have shown that income risks to a persistent component are having a larger impact on an individual's consumption and investment strategies than income risks to a temporary component (Kimball, 1993; Koo, 1998; Elmendorf and Kimball, 2000; Angerer and Lam, 2009). Along this line, this paper focuses on the effects of permanent component of unemployment risks.

${ }^{18}$ The unemployment event is assumed to occur at the first jump time of Poisson arrival, which is independent of the Brownian motion $W(t)$. The contemporaneous correlation between stock market and labor income is independent, which is consistent with the data (Cocco et al., 2005; Benzoni et al., 2007). Returns to the present value of labor income are highly correlated with market returns. We can relax our independence assumption by considering a stochastically-changing process of $\delta$ and our main results are robust against such a change of assumption. It is well documented that mortality, disability, retirement, unemployment, and many other disastrous events occur at an uncertain time, so $\tau_{U}$ following an exponential
} 
with a stochastic labor income stream $I(t)$, which evolves as

$$
I(t)=\left\{\begin{array}{l}
I_{1}, \quad \text { if } 0 \leq t<\tau \wedge \tau_{U}, \\
I_{2}, \quad \text { if } t \geq \tau \wedge \tau_{U},
\end{array}\right.
$$

where $\tau$ is the voluntary retirement time. As a result, the individual has the following expected human wealth prior to retirement:

$$
E\left[\int_{0}^{\tau_{U}} e^{-r t} I(t) d t\right]=\frac{1}{r+\delta}\left(I_{1}+I_{2} \frac{\delta}{r}\right)
$$

which is adjusted by the intensity $\delta$ for an unemployment event. Here, the discount rate is adjusted by the perceived unemployment risk, i.e., $r+\delta$. Comparing to human wealth (1), human wealth (3) is lower, which is the present value of the sum of labor income $I_{1}$ and post-retirement income $I_{2} \frac{\delta}{r}$, (adjusted by the unemployment intensity $\delta$ ), and discounted by the sum of risk-free interest rate $r$ and unemployment intensity $\delta$.

We assume that there are no sufficient financial instruments (e.g., securities, financial contracts, or insurance contracts) to fully hedge against the unemployment risk. Social securities and private insurance market are insufficient to perfectly hedge against large and negative wealth shocks (Gormley et al., 2010) and labor income risks (Cocco et al., 2005). In this regard, we assume that social security can insure only parts (but not all) of the individual's labor income after forced unemployment. ${ }^{19}$ Accordingly, the financial market is essentially incomplete.

distribution can appropriately account for such a uncertain lifetime (Merton, 1971; Viceira, 2001).

${ }^{19}$ This assumption has been used in previous standard life-cycle models (Carroll et al., 2003; Cocco et al., 2005; Lynch and Tan, 2011). Carroll et al. (2003) assume that formal and informal insurance markets provide a safety net against unemployment risk and consider the unemployment income to be $20 \%$ of permanent labor income in the periods of unemployment. Lynch and Tan (2011) also assume 


\subsection{Borrowing Constraints}

The individual accumulates her wealth $X(t)$ with initial wealth $X(0)=x$ given the following dynamic budget constraints:

$$
d X(t)=(r X(t)-c(t)+I(t)) d t+\pi(t) \sigma(d W(t)+\theta d t)
$$

where $\pi(t)$ is the dollar amount invested in the stock, $\theta$ denotes the Sharpe ratio $((\mu-r) / \sigma)$, and $I(t)$ is a stochastic labor income stream formulated by (2).

Throughout the paper, we impose borrowing constraints before voluntary retirement or forced unemployment as follows:

$$
X(t) \geq 0 \text { for } 0 \leq t<\tau \wedge \tau_{U}
$$

which restricts unsecured borrowing against the present value of stochastic labor income.

Following forced unemployment, we assume that the individual could borrow up to the present value of the lowest possible post-retirement income $I_{2}$, which can be an annuitized payout from a Social Security program or subsistence such as public welfare or unemployment allowance provided by the government. ${ }^{20}$ Hence, the individual has the following that income in persistent unemployment state is $10 \%$ of permanent labor income. In reality, income after retirement can be annuity payments from a Social Security program or subsistence such as public welfare or unemployment allowances provided by the government.

${ }^{20}$ This consideration is consistent with the conventional economic stimulus during economic downturns, targeted at poor people and especially at the unemployed, that has turned out to be effective in building aggregate spending (Carroll et al., 2015). 
present value of post-retirement income discounted by the risk-free interest rate: ${ }^{21}$

$$
E\left[\int_{0}^{\infty} e^{-r t} I_{2} d t\right]=\frac{I_{2}}{r} .
$$

We thus allow for borrowing after voluntary retirement or forced unemployment as the following: $:^{22}$

$$
X(t) \geq-\frac{I_{2}}{r} \text { for } t \geq \tau \wedge \tau_{U}
$$

Moving forward, we consider only the admissible investment and consumption strategies

${ }^{21}$ Although the value of annuity jumps to zero upon death, the future annuity payments still have the present value $I_{2} /(r+\nu)$, which is the discounted value of future annuity payments by the constant discount factor with the constant hazard rate $\nu$ of death. More specifically,

$$
\begin{aligned}
& E\left[\int_{0}^{\tau_{M}} e^{-r t} I_{2} d t\right] \\
& \quad=E\left[\int_{0}^{\infty} \nu e^{-\nu s} \int_{0}^{s} e^{-r t} I_{2} d t d s\right] \\
& \quad=E\left[\int_{0}^{\infty} e^{-r t} I_{2} \int_{t}^{\infty} \nu e^{-\nu s} d s d t\right] \\
& =E\left[\int_{0}^{\infty} e^{-(r+\nu) t} I_{2} d t\right] \\
& =\frac{I_{2}}{r+\nu},
\end{aligned}
$$

where $\tau_{M}$ follows an exponential distribution with $\nu>0$.

${ }^{22}$ One can consider the non-borrowing situation after either the voluntary or involuntary retirement. Such an additional borrowing constraint may affect the pre-retirement optimal strategies in a nontrivial way, thereby reinforcing the effects of forced unemployment risk. The technical difficulty is that the postretirement value function no longer has a closed-form as in Merton $(1969,1971)$, so one needs to solve it numerically, which adds an extra technical difficulty when solving the pre-retirement value function with forced unemployment risk and borrowing constraints. Ours is a first step to establish the two-dimensional framework before retirement. With such a framework, the borrowing constraints after retirement can also be considered. 
$\{\pi(t), c(t)\}$ that satisfy the dynamic budget constraint (4) subject to the borrowing constraints (5) and (6).

\subsection{An Optimal Retirement Model}

An optimal retirement model with borrowing constraints and forced unemployment risk is to maximize the individual's life-time utility of consumption by optimally managing perperiod consumption $c$, risky investment $\pi$, and voluntary retirement time $\tau$. Specifically, the individual with initial wealth $x \geq 0$ aims to maximize the following value function $(\mathrm{BJP}):{ }^{23}$

$$
\Phi(x) \equiv \max _{(c, \pi, \tau)} E\left[\int_{0}^{\tau \wedge \tau_{U}} e^{-\beta t} \ln c(t) d t+e^{-\beta\left(\tau \wedge \tau_{U}\right)} \int_{\tau \wedge \tau_{U}}^{\infty} e^{-\beta\left(t-\tau \wedge \tau_{U}\right)} \ln (K c(t)) d t\right]
$$

where $\beta>0$ is the individual's subjective discount rate, and $K>1$ is the preference for leisure as defined earlier. For simplicity, we assume that the individual has no bequest motive. $^{24}$

We define the value function of the individual who receives income at the rate equal to $I_{2}$ infinitely as the following:

$$
U_{2}\left(X\left(\tau \wedge \tau_{U}\right)\right) \equiv \max _{(c, \pi)} E\left[\int_{\tau \wedge \tau_{U}}^{\infty} e^{-\beta\left(t-\tau \wedge \tau_{U}\right)} \ln (K c(t)) d t\right] .
$$

\footnotetext{
${ }^{23}$ We consider an infinite-horizon life-cycle model; as a result, we overestimate the effects of unemployment risk in that our representation of forced unemployment is more painful than it actually is because unemployed people undergo a drastic and permanent reduction of income.

${ }^{24}$ The presence of the bequest motive reinforces the negative effects of income reduction when forced unemployment takes place.
} 
Let $s=\tau \wedge \tau_{U}$. Then

$$
U_{2}(X(s))=\max _{(c, \pi)} E\left[\int_{s}^{\infty} e^{-\beta(t-s)} \ln (K c(t)) d t\right]
$$

Using the dynamic programming approach of Merton $(1969,1971)$ or the martingale approach of Cox and Huang (1989), we obtain

$$
U_{2}(X(s))=\frac{1}{\beta}\left[\ln \left(X(s)+\frac{I_{2}}{r}\right)+\frac{1}{\beta}\left(r+\frac{\theta^{2}}{2}-\beta(1-\ln K)\right)+\ln \beta\right] .
$$

Further, using the principle of dynamic programming, we can rewrite the value function $\Phi(x)$ given in (7) as the following:

$$
\Phi(x)=\max _{(c, \pi, \tau)} E\left[\int_{0}^{\tau \wedge \tau_{U}} e^{-\beta t} \ln c(t) d t+e^{-\beta\left(\tau \wedge \tau_{U}\right)} U_{2}\left(X\left(\tau \wedge \tau_{U}\right)\right)\right] .
$$

The conditional expectation of $\tau_{U}$ allows us to restate the value function in $(7)$ as the following: ${ }^{25}$

$$
\Phi(x)=\max _{(c, \pi, \tau)} E\left[\int_{0}^{\tau} e^{-(\beta+\delta) t}\left\{\ln c(t)+\delta U_{2}(X(t))\right\} d t+e^{-(\beta+\delta) \tau} U_{2}(X(\tau))\right] .
$$

\footnotetext{
${ }^{25}$ After integrating out $\tau_{U}$ using its conditional expectation, it seems that voluntary retirement time $\tau$ does not depend on forced unemployment time $\tau_{U}$. However, $\tau_{U}$ interacts with $\tau$ in a significant way through forced unemployment intensity $\delta$, which causes an increase of subjective discount rate $\beta$ by the amount of $\delta$ and accompanies the post-retirement value function $U_{2}$. Consequently, the extra terms involving $\delta$ caused by $\tau_{U}$ affect the optimal life-cycle consumption, investment, and retirement decisions. For a more realistic life-cycle model, one may relax the assumption that the forced unemployment intensity is constant. Rather, it should be time-varying as unemployment risk fluctuates in business cycles. For example, one can allow for a highly nonlinear intensity into forced unemployment by considering an additional stochastic process for $\delta$.
} 
The value function in (8) reduces to the value function of BJP without considering the borrowing constraints and thus, initial wealth $x$ could be larger than or equal to $-I_{1} / r\left(x \geq-I_{1} / r\right)$, which is the human wealth in (1). However, as BJP acknowledges, the presence of forced unemployment risk makes the retirement problem in (8) harder to be well defined. In particular, the individual can be involuntarily retired due to forced unemployment with substantial negative wealth lower than $-I_{2} / r$, where the term involving $U_{2}(X(t))$ inside the integrand on the right-hand side of $(8)$ is not defined at all and becomes $-\infty$ as intermediate wealth $X(t)$ at time $t$ approaches $-I_{2} / r \cdot{ }^{26}$ The borrowing constraints in (5) makes the retirement problem in (8) well defined, where the term involving $U_{2}(X(t))$ has finite values as wealth $X(t)$ at time $t$ approaches zero.

\section{The Solution}

\subsection{Problem Reformulation}

Our optimal retirement problem in (8) is the optimal stopping problem formulated by

$$
\Phi(x) \equiv \max _{\tau} J_{\tau}(x)
$$

\footnotetext{
${ }^{26}$ To bound the value function, BJP has modeled forced unemployment risk with the piecewise connected utility function. With the piecewise connected utility function (i.e., when the individual is risk averse for positive wealth, while becomes indifferent to negative wealth), the boundedness of the first derivative of $U_{2}$ is still guaranteed even when wealth approaches its lower limit.
} 
where

$$
J_{\tau}(x) \equiv \max _{(c, \pi)} E\left[\int_{0}^{\tau} e^{-(\beta+\delta) t}\left\{\ln c(t)+\delta U_{2}(X(t))\right\} d t+e^{-(\beta+\delta) \tau} U_{2}(X(\tau))\right]
$$

for a fixed stopping time $\tau$. To solve the optimal stopping problem, we adopt the widely used variational inequality approach of Bensoussan and Lions (1982) and Øksendal (2007). According to this approach, the solution to the optimal stopping problem is equivalent to the solution to the variational inequality, which characterizes two separate regions: the continuation region and the stopping region. Here, there exists a free boundary that determines the two regions.

We first derive the variational inequality of the optimal stopping problem. For any $x \geq 0$

$$
\left\{\begin{array}{l}
(\beta+\delta) \phi(x)-\left(r x+I_{1}\right) \phi^{\prime}(x)+\frac{\theta^{2}}{2} \frac{\phi^{\prime}(x)^{2}}{\phi^{\prime \prime}(x)}+1+\ln \phi^{\prime}(x) \geq \delta U_{2}(x) \\
\phi(x) \geq U_{2}(x) \\
{\left[(\beta+\delta) \phi(x)-\left(r x+I_{1}\right) \phi^{\prime}(x)+\frac{\theta^{2}}{2} \frac{\phi^{\prime}(x)^{2}}{\phi^{\prime \prime}(x)}+1+\ln \phi^{\prime}(x)-\delta U_{2}(x)\right]\left(\phi(x)-U_{2}(x)\right)=0 .}
\end{array}\right.
$$

The variational inequality indeed characterizes the two regions. On the one hand, the individual continues to work and receive labor income, i.e., she is in the work region. On the other hand, the individual enters voluntary retirement, i.e., she is in the retirement region. The first inequality in (9) shows that the equality holds in the work region, and the strict inequality holds in the retirement region. As long as the value function before retirement is larger than the value function after retirement, the strict inequality of the second inequality holds. As a result, the individual is in the work region and will opt for 
retirement when she accumulates enough wealth. As the value function before retirement approaches the value function after retirement, the equality of the second inequality holds and hence, the individual is in the retirement region and enters voluntary retirement. Note that since either the first inequality or the second inequality holds, the final inequality in (9) should be satisfied for any values of $x \geq 0$.

It turns out that the work region and the retirement region can be characterized by the popularly termed critical wealth level, over which it is optimal to enter voluntary retirement. We conjecture that the optimal stopping problem formulated by variational inequalities in (9) can be solved by finding a free boundary $\hat{x}$ that represents the critical wealth level for retirement. Specifically,

$$
\left\{\begin{array}{l}
(\beta+\delta) \phi(x)-\left(r x+I_{1}\right) \phi^{\prime}(x)+\frac{\theta^{2}}{2} \frac{\phi^{\prime}(x)^{2}}{\phi^{\prime \prime}(x)}+1+\ln \phi^{\prime}(x)=\delta U_{2}(x), \quad 0 \leq x<\hat{x}, \\
\phi(x)=U_{2}(x), \quad x \geq \hat{x} \\
\phi(\hat{x})=U_{2}(\hat{x}), \\
\phi^{\prime}(\hat{x})=\frac{1}{\beta} \frac{1}{\hat{x}+I_{2} / r} .
\end{array}\right.
$$

The free boundary problem (10) significantly differs from that of BJP in that initial wealth $x$ is always larger than or equal to zero, which represents the borrowing constraints. If we can find a unique solution $\phi(x)$ of (10) that is $C^{1}$ and piecewise $C^{2}$, then it can also satisfy the variational inequalities in (9). Note that the solution $\phi(x)$ becomes the value function in our retirement problem (8) following Theorem 10.4.1 in Øksendal (2007).

To solve the problem, we reformulate the problem by introducing a new state variable instead of financial wealth $x$. Following BJP, let $\lambda(x)$ be the first derivative of the value 
function $\phi(x)$. Next, we associate the total wealth $x+I_{1} / r$ (the sum of financial wealth and human wealth) with a convex-dual function $G(\lambda(x)):{ }^{27}$

$$
G(\lambda(x)) \equiv x+\frac{I_{1}}{r}
$$

Note that the following relations hold:

$$
G^{\prime}(\lambda(x)) \lambda^{\prime}(x)=1
$$

and

$$
G^{\prime \prime}(\lambda(x)) \lambda^{\prime}(x)^{2}+G^{\prime}(\lambda(x)) \lambda^{\prime \prime}(x)=0 .
$$

Also, the boundary condition of $\phi^{\prime}(x)$ at $\hat{x}$ in (10) results in

$$
\underline{\lambda} \equiv \phi^{\prime}(\hat{x})=\frac{1}{\beta\left(\hat{x}+I_{2} / r\right)} .
$$

In BJP, the individual is allowed to borrow against future labor income, i.e.,

$$
x \geq-\frac{I_{1}}{r},
$$

as a result, $G(\lambda(x))$ becomes zero as financial wealth $x$ approaches $-I_{1} / r$. In this paper, however, the individual is subject to borrowing constraints, i.e.,

$$
x \geq 0,
$$

\footnotetext{
${ }^{27}$ The convexity of $G$ is hard to prove, but it is numerically verified with a wide range of parameter values. In the Online Appendix, we theoretically prove that $G$ is a monotonically decreasing function with somewhat complex parameter conditions. Further, $G$ also has a dual relation with the value function $\phi$ according to the definition of $\lambda$ as the first derivative of $\phi$.
} 
and hence, there exists an upper bound $\bar{\lambda}$ at which $G(\lambda(x))$ becomes $I_{1} / r$. Thus, we can reformulate the problem (10) using $\lambda(x)$ instead of $x$. In particular, when differentiating both sides of the first equation in (10) with respect to $x$, we obtain the following equation for $\underline{\lambda}<\lambda(x)<\bar{\lambda}$ :

$$
-\frac{1}{2} \theta^{2} \lambda^{2} G^{\prime \prime}(\lambda)-\lambda G^{\prime}(\lambda)\left(\theta^{2}+\beta+\delta-r\right)+r G(\lambda)+\frac{\delta}{\beta} \frac{G^{\prime}(\lambda)}{G(\lambda)-I_{1} / r+I_{2} / r}=\frac{1}{\lambda}
$$

where we have used $\lambda$ instead of $\lambda(x)$ for notational simplicity. The definition (11) of $G(\lambda)$ and the relations between $\underline{\lambda}$ and $\hat{x}$ give the boundary condition of $G(\lambda)$ at $\underline{\lambda}$ :

$$
G(\underline{\lambda})=\frac{1}{\beta \underline{\lambda}}+\frac{I_{1}-I_{2}}{r}
$$

Also, borrowing constraints lead to two boundary conditions:

$$
G(\bar{\lambda})=\frac{I_{1}}{r}, \quad G^{\prime}(\bar{\lambda})=0
$$

where the boundary condition of $G^{\prime}(\lambda)$ at $\bar{\lambda}$ is derived from the fact that risky investment becomes zero as $\lambda$ approaches $\bar{\lambda}$, i.e., as financial wealth $x$ reaches zero (Dybvig and Liu, $2011) .^{28}$

In sum, our retirement problem in (8) is reformulated by a nonlinear differential equation (13) with boundary conditions in (14) and (15). In the Online Appendix, we prove the existence of the solution of (13) satisfying $C^{1}$ and $C^{2}$ for any $\underline{\lambda}>0, \bar{\lambda}>0$. If we can find

\footnotetext{
${ }^{28}$ Specifically, the optimality condition for risky investment is given by
}

$$
\pi^{*}(t)=-\frac{\theta}{\sigma} \frac{\phi^{\prime}(x)}{\phi^{\prime \prime}(x)}=-\frac{\theta}{\sigma} \lambda G^{\prime}(\lambda)
$$

accordingly, the boundary condition of $G^{\prime}(\bar{\lambda})$ is equivalent to zero risky investment. 
such a solution analytically or numerically, we can then determine the two free boundaries according to the boundary conditions in (14) and (15). We also prove the uniqueness of the solution of (13) with some parameter conditions including the two free boundaries. Having determined these free boundaries, it is straightforward to check whether or not the conditions hold with reasonable parameter values. In Section 4, we confirm that the conditions are valid with carefully chosen parameter values and their perturbations, and thereby the resulting optimal strategies are clearly visualized.

\subsection{Solution}

Given the reformulated retirement problem (13) with boundary conditions in (14) and (15), we aim to find a solution to the problem.

A general solution. To derive a general solution of (13), we define two constants $\alpha_{\delta}>1$ and $-1<\alpha_{\delta}^{*}<0$ as the two roots of

$$
F(\alpha ; \delta) \equiv-\frac{1}{2} \theta^{2} \alpha(\alpha-1)+\alpha(\beta+\delta-r)+r=0
$$

Next, we conjecture the general solution as follows:

$$
G(\lambda)=\frac{1}{\lambda(\beta+\delta)}+A(\lambda) \lambda^{-\alpha_{\delta}}+A^{*}(\lambda) \lambda^{-\alpha_{\delta}^{*}}
$$

subject to

$$
A^{\prime}(\lambda) \lambda^{-\alpha_{\delta}}+\left(A^{*}(\lambda)\right)^{\prime} \lambda^{-\alpha_{\delta}^{*}}=0 .
$$


Putting the conjectured solution into (13) results in the following for $\underline{\lambda}<\lambda<\bar{\lambda}$ :

$$
\begin{aligned}
G(\lambda)= & \frac{1}{\lambda(\beta+\delta)}+B(\underline{\lambda}) \lambda^{-\alpha_{\delta}}+B^{*}(\bar{\lambda}) \lambda^{-\alpha_{\delta}^{*}} \\
& +\frac{2 \delta\left(\alpha_{\delta}-1\right)}{\theta^{2}\left(\alpha_{\delta}-\alpha_{\delta}^{*}\right) \beta} \lambda^{-\alpha_{\delta}} \int_{\underline{\lambda}}^{\lambda} \mu^{\alpha_{\delta}-2} \ln \left(G(\mu)-\frac{I_{1}}{r}+\frac{I_{2}}{r}\right) d \mu \\
& +\frac{2 \delta\left(\alpha_{\delta}^{*}-1\right)}{\theta^{2}\left(\alpha_{\delta}-\alpha_{\delta}^{*}\right) \beta} \lambda^{-\alpha_{\delta}^{*}} \int_{\lambda}^{\bar{\lambda}} \mu^{\alpha_{\delta}^{*}-2} \ln \left(G(\mu)-\frac{I_{1}}{r}+\frac{I_{2}}{r}\right) d \mu
\end{aligned}
$$

where

$$
\begin{aligned}
& B(\underline{\lambda}) \equiv A(\underline{\lambda})-\frac{2 \delta}{\theta^{2}\left(\alpha_{\delta}-\alpha_{\delta}^{*}\right)} \underline{\lambda}^{\alpha_{\delta}-1} \ln \left(G(\underline{\lambda})-\frac{I_{1}}{r}+\frac{I_{2}}{r}\right)+\frac{2 \delta}{\theta^{2}\left(\alpha_{\delta}-\alpha_{\delta}^{*}\right) \beta} \underline{\lambda}^{\alpha_{\delta}-1} \ln \frac{1}{\underline{\lambda}}, \\
& B^{*}(\bar{\lambda}) \equiv A^{*}(\bar{\lambda})-\frac{2 \delta}{\theta^{2}\left(\alpha_{\delta}-\alpha_{\delta}^{*}\right) \beta} \bar{\lambda}^{\alpha_{\delta}^{*}-1} \ln \left(\frac{I_{2}}{r}\right)+\frac{2 \delta}{\theta^{2}\left(\alpha_{\delta}-\alpha_{\delta}^{*}\right) \beta} \bar{\lambda}^{\alpha_{\delta}^{*}-1} \ln \left(G(\bar{\lambda})-\frac{I_{1}}{r}+\frac{I_{2}}{r}\right) .
\end{aligned}
$$

The value-matching condition $\phi(\hat{x})=U_{2}(\hat{x})$ in $(10)$ gives rise to

$$
\ln K=\underline{\lambda}\left(I_{1}-I_{2}\right)\left(1+\frac{\theta^{2} \alpha_{\delta}^{*}}{2 r}\right)+\frac{\delta}{\beta} \ln \underline{\lambda}+\frac{\theta^{2}\left(\alpha_{\delta}-\alpha_{\delta}^{*}\right)}{2} B(\underline{\lambda}) \underline{\lambda}^{-\alpha_{\delta}-1} .
$$

The boundary conditions in (15) leads to the following two equations:

$$
\begin{aligned}
\frac{I_{1}}{r}=\frac{1}{\bar{\lambda}(\beta+\delta)} & +B(\underline{\lambda}) \bar{\lambda}^{-\alpha_{\delta}}+B^{*}(\bar{\lambda}) \bar{\lambda}^{-\alpha_{\delta}^{*}}+\frac{2 \delta\left(\alpha_{\delta}-1\right) \bar{\lambda}^{-\alpha_{\delta}}}{\theta^{2}\left(\alpha_{\delta}-\alpha_{\delta}^{*}\right) \beta} \int_{\underline{\lambda}}^{\bar{\lambda}} \mu^{\alpha_{\delta}-2} \ln \left(G(\mu)-\frac{I_{1}}{r}+\frac{I_{2}}{r}\right) d \mu, \\
0= & -\frac{1}{\bar{\lambda}^{2}(\beta+\delta)}-\alpha_{\delta} B(\underline{\lambda}) \bar{\lambda}^{-\alpha_{\delta}-1}-\alpha_{\delta}^{*} B^{*}(\bar{\lambda}) \bar{\lambda}^{-\alpha_{\delta}^{*}-1}+\frac{2 \delta}{\theta^{2} \beta \bar{\lambda}^{2}} \ln \left(\frac{I_{2}}{r}\right) \\
& -\frac{2 \delta \alpha_{\delta}\left(\alpha_{\delta}-1\right) \bar{\lambda}^{-\alpha_{\delta}-1}}{\theta^{2}\left(\alpha_{\delta}-\alpha_{\delta}^{*}\right)} \int_{\underline{\lambda}}^{\bar{\lambda}} \mu^{\alpha_{\delta}-2} \ln \left(G(\mu)-\frac{I_{1}}{r}+\frac{I_{2}}{r}\right) d \mu .
\end{aligned}
$$

Rearranging the above two equations results in

$$
\frac{\alpha_{\delta}-1}{\beta+\delta}+\frac{2 \delta}{\theta^{2} \beta} \ln \left(\frac{I_{2}}{r}\right)=\frac{\alpha_{\delta} I_{1}}{r} \bar{\lambda}-\left(\alpha_{\delta}-\alpha_{\delta}^{*}\right) B^{*}(\bar{\lambda}) \bar{\lambda}^{-\alpha_{\delta}^{*}+1}
$$

The equations (17) and (18) yield the system of two algebraic equations with $\underline{\lambda}$ and $\bar{\lambda}$ as 
the following:

$$
\begin{aligned}
& \frac{I_{1}-I_{2}}{r}+\left(I_{1}-I_{2}\right)\left(1+\frac{\theta^{2} \alpha_{\delta}^{*}}{2 r}\right) \frac{2}{\theta^{2}\left(\alpha_{\delta}-\alpha_{\delta}^{*}\right)} \\
&= \frac{1}{\underline{\lambda}(\beta+\delta)}-\frac{1}{\beta \underline{\lambda}}+\left\{\frac{\ln K}{\underline{\lambda}}-\frac{\delta \ln \underline{\lambda}}{\beta \underline{\lambda}}\right\} \frac{2}{\theta^{2}\left(\alpha_{\delta}-\alpha_{\delta}^{*}\right)} \\
&+\left[\frac{\alpha_{\delta} I_{1}}{r \bar{\lambda}}-\left\{\frac{\alpha_{\delta}-1}{\beta+\delta}+\frac{2 \delta}{\theta^{2} \beta} \ln \left(\frac{I_{2}}{r}\right)\right\} \frac{1}{\bar{\lambda} 2}\right] \frac{1}{\left(\alpha_{\delta}-\alpha_{\delta}^{*}\right)}\left(\frac{\bar{\lambda}}{\underline{\lambda}}\right)^{\alpha_{\delta}^{*}} \bar{\lambda} \\
&+\frac{2 \delta\left(\alpha_{\delta}^{*}-1\right) \underline{\lambda^{-\alpha_{\delta}^{*}}}}{\theta^{2}\left(\alpha_{\delta}-\alpha_{\delta}^{*}\right) \beta} \int_{\underline{\lambda}}^{\bar{\lambda}} \mu^{\alpha_{\delta}^{*}-2} \ln \left(G(\mu)-\frac{I_{1}}{r}+\frac{I_{2}}{r}\right) d \mu \\
&-\frac{I_{1}}{r} \frac{\alpha_{\delta}^{*}}{\left(\alpha_{\delta}-\alpha_{\delta}^{*}\right)} \\
&=\frac{1}{\bar{\lambda}(\beta+\delta)}+\left\{\ln K-\left(I_{1}-I_{2}\right)\left(1+\frac{\theta^{2} \alpha_{\delta}^{*}}{2 r}\right) \underline{\lambda}-\frac{\delta}{\beta} \ln \underline{\lambda}\right\} \frac{2}{\theta^{2}\left(\alpha_{\delta}-\alpha_{\delta}^{*}\right)}\left(\frac{\bar{\lambda}}{\bar{\lambda}}\right)^{\alpha_{\delta}} \frac{1}{\underline{\lambda}} \\
&-\left[\left\{\frac{\alpha_{\delta}-1}{\beta+\delta}+\frac{2 \delta}{\theta^{2} \beta} \ln \left(\frac{I_{2}}{r}\right)\right\}\right.\left.\frac{1}{\bar{\lambda}}\right] \frac{1}{\left(\alpha_{\delta}-\alpha_{\delta}^{*}\right)}+\frac{2 \delta\left(\alpha_{\delta}-1\right) \bar{\lambda}^{-\alpha_{\delta}}}{\theta^{2}\left(\alpha_{\delta}-\alpha_{\delta}^{*}\right) \beta} \int_{\underline{\lambda}}^{\bar{\lambda}} \mu^{\alpha_{\delta}-2} \ln \left(G(\mu)-\frac{I_{1}}{r}+\frac{I_{2}}{r}\right) d \mu .
\end{aligned}
$$

An iterative numerical algorithm. We now need to determine the two free boundaries $\underline{\lambda}$ and $\bar{\lambda}$ with $G(\lambda)$ in (19) and (20) numerically. We develop an iterative numerical algorithm as follows. ${ }^{29}$

- (Step 0) Suppose $\delta=0$, i.e., when we do not allow for forced unemployment risk, we can easily obtain $B(\underline{\lambda})$ and $B^{*}(\bar{\lambda})$ from $(17)$ and (18), respectively. Thus, we can get $G(\lambda)$ from (16). Putting $G(\lambda)$ into the system comprised of two equations (19) and (20), we can determine $\underline{\lambda}$ and $\bar{\lambda}$, numerically.

\footnotetext{
${ }^{29}$ In the Online Appendix, the convergence of the proposed numerical algorithm is shown by the Banach fixed-point theorem.
} 
- (Step 1) Suppose a sufficiently small positive value $\delta$, i.e., when we allow for forced unemployment risk. We exploit $G(\lambda), \underline{\lambda}$, and $\bar{\lambda}$ for the case where $\delta=0$ as the initial values for our numerical algorithm.

- (Step 2) Using the initial values, we update $B(\underline{\lambda})$ and $B^{*}(\bar{\lambda})$ from (17) and (18), respectively. We also update $G(\lambda)$ from (16) with the updated $B(\underline{\lambda})$ and $B^{*}(\bar{\lambda})$.

- (Step 3) Putting the updated $G(\lambda)$ into the system that consists of two equations (19) and (20), we can determine $\underline{\lambda}$ and $\bar{\lambda}$, numerically.

- (Step 4) Repeat the above steps 1,2, and 3 until $\underline{\lambda}$ and $\bar{\lambda}$ converge.

\subsection{Optimal Strategies}

Having solved the retirement problem (8) or equivalently, the nonlinear differential equation (13) with boundary conditions (14) and (15), we provide analytic results for the optimal strategies.

Optimal Wealth Accumulation. We present explicit expressions for (and various properties of) optimal wealth of the individual who faces forced unemployment risk and is borrowing constrained.

Theorem 3.1 The time-t optimal wealth is derived in closed-form prior to voluntary re- 
tirement, i.e., for $0 \leq X(t)<\hat{x}$,

$$
\begin{aligned}
X(t)+\frac{I_{1}}{r}= & \{\underbrace{\frac{c(t)}{\beta+\delta}}_{\text {consumption savings }}\}+\{\underbrace{B(\underline{\lambda}) \lambda(X(t))^{-\alpha_{\delta}}}_{\text {retirement-induced savings }}\} \\
+ & \{\underbrace{B^{*}(\bar{\lambda}) \lambda(X(t))^{-\alpha_{\delta}^{*}}}_{\text {borrowing-constraints-induced savings }}\}+U,
\end{aligned}
$$

where $U$ represents unemployment-risk-induced savings and it is given by

$$
\begin{gathered}
U=U 1+U 2, \\
U 1=\frac{2 \delta\left(\alpha_{\delta}-1\right)}{\theta^{2}\left(\alpha_{\delta}-\alpha_{\delta}^{*}\right) \beta} \lambda(X(t))^{-\alpha_{\delta}} \int_{\underline{\lambda}}^{\lambda(X(t))} \mu^{\alpha_{\delta}-2} \ln \left(G(\mu)-\frac{I_{1}}{r}+\frac{I_{2}}{r}\right) d \mu \\
U 2=\frac{2 \delta\left(\alpha_{\delta}^{*}-1\right)}{\theta^{2}\left(\alpha_{\delta}-\alpha_{\delta}^{*}\right) \beta} \lambda(X(t))^{-\alpha_{\delta}^{*}} \int_{\lambda(X(t))}^{\bar{\lambda}} \mu^{\alpha_{\delta}^{*}-2} \ln \left(G(\mu)-\frac{I_{1}}{r}+\frac{I_{2}}{r}\right) d \mu .
\end{gathered}
$$

Proof. See Proofs in the Online Appendix. Q.E.D.

Theorem 3.1 explicitly decomposes the time- $t$ optimal wealth into four savings motives: (i) consumption savings, (ii) retirement-induced savings, (iii) borrowing-constraintsinduced savings, and (iv) unemployment-risk-induced savings.

If we consider only the consumption savings motive, we can easily revisit the classic permanent-income-hypothesis (PIH) of Friedman (1957):

$$
c(t)=(\beta+\delta)\left(X(t)+\frac{I_{1}}{r}\right)
$$

It shows that the individual's optimal consumption is determined by the annuity value of total wealth comprised of time-t financial wealth $X(t)$ and human wealth $I_{1} / r$.

In addition to the consumption savings motive, when we consider retirement-induced savings motive, the option-based analysis in Farhi and Panageas (2007) provides an intuitive interpretation of the time- $t$ optimal wealth in (21). Voluntary retirement can be 
viewed as an American-style option that allows the individual to exchange the value of labor income with extra leisure that is brought about by entering retirement. Since the time-t optimal wealth acts as an underlying asset of such option and subsequently, controls the distance to retirement, the retirement-induced savings become increasingly large as wealth $X(t)$ approaches a certain threshold $\hat{x}$ or equivalently, as $\lambda(X(t))$ reaches $\underline{\lambda}$.

In the presence of borrowing constraints against future labor income, the individual is responsible for keeping the time- $t$ wealth above zero. In other words, the individual maintains her time-t optimal wealth to be larger than zero in all states (Dybvig and Liu, 2010). The individual responds more actively to changes in the state variable $\lambda(X(t))$ that affect her chance of ending up with $X(t) \leq 0$. That is, the individual accumulates more wealth as $X(t)$ approaches zero or equivalently, as $\lambda(X(t))$ reaches $\bar{\lambda}$.

Unlike Dybvig and Liu (2010), we show that borrowing constraints and forced unemployment risk jointly affect the individual's time- $t$ optimal wealth. The individual's hedging demand results from two sources: the stock market risk and the forced unemployment risk. We find that the individual under the two-dimensional market incompleteness can have excess hedging demand that results in excess wealth accumulation to avoid binding borrowing constraints, and to cope with unexpected hardship in the aftermath of forced unemployment.

In the presence of forced unemployment risk, i.e., when $\delta>0$, the individual accumulates time- $t$ optimal wealth non-myopically with respect to potential unemployment shock. In anticipation of future disastrous income shock, the unemployment-risk-induced savings motive becomes significant. In particular, the savings motive has two parts. The first 
term that involves $\underline{\lambda}$ is associated with the savings motive for retirement with a likelihood of unemployment. The second term that involves $\bar{\lambda}$ is related to the savings motive for maintaining the time- $t$ optimal wealth above zero with a likelihood of unemployment.

We demonstrate that the negative effect of forced unemployment risk becomes larger as the time- $t$ optimal wealth approaches zero or equivalently, $\lambda(X(t))$ reaches $\bar{\lambda}$, and the savings motive becomes stronger. In contrary, the effect of unemployment risk becomes negligible as the wealth approaches the critical wealth threshold $\hat{x}$ or equivalently, $\lambda(X(t))$ reaches $\underline{\lambda}$ and the savings motive becomes weaker, implying more consumption or investment. In the intermediate region, i.e., $0<X(t)<\hat{x}$, the effect of forced unemployment risk exhibits convexity in $\lambda(X(t))$, and it is worth investigating how this convexity will increase or decrease as the individual accumulates her wealth. We show that in these intermediate states, the individual should begin to insure herself by optimally accumulating wealth.

We can perform a simple exercise to demonstrate the impacts of joint consideration of borrowing constraints and forced unemployment risk on time-t optimal wealth. Suppose that the forced unemployment takes place and the individual is now unemployed with available wealth $x^{*}$ between zero and $\hat{x}$. Using the definition (11) of $G(\lambda(x))$, we obtain

$$
G\left(\lambda^{*}\right)=x^{*}+\frac{I_{1}}{r}
$$

where, for simplicity, we use $\lambda^{*}$ instead of $\lambda\left(x^{*}\right)$. Then, the unemployment-risk-induced savings term becomes

$$
\begin{aligned}
& \frac{2}{\theta^{2}\left(\alpha_{\delta}-\alpha_{\delta}^{*}\right)}\left\{\frac{\delta}{\beta} \ln \left(x^{*}+\frac{I_{2}}{r}\right)\right\} c(t)\left\{1-\left(\frac{\lambda}{\lambda^{*}}\right)^{\alpha_{\delta}-1}\right\} \\
& -\frac{2}{\theta^{2}\left(\alpha_{\delta}-\alpha_{\delta}^{*}\right)}\left\{\frac{\delta}{\beta} \ln \left(x^{*}+\frac{I_{2}}{r}\right)\right\} c(t)\left\{1-\left(\frac{\bar{\lambda}}{\lambda^{*}}\right)^{\alpha_{\delta}^{*}-1}\right\} .
\end{aligned}
$$


In the presence of forced unemployment risk, the individual accumulates wealth to finance consumption needs in the aftermath of unemployment, which are adjusted by the utility value from current available resources $x^{*}+I_{2} / r$. For levels of wealth close to zero, the unemployment-risk-induced savings term approaches

$$
\frac{2}{\theta^{2}\left(\alpha_{\delta}-\alpha_{\delta}^{*}\right)}\left\{\frac{\delta}{\beta} \ln \left(\frac{I_{2}}{r}\right)\right\} c(t)\left\{1-\left(\frac{\lambda}{\bar{\lambda}}\right)^{\alpha_{\delta}-1}\right\}>0 .
$$

This positive savings demand for the preparedness after unemployment highlights the importance of borrowing constraints. As a result of the two-dimensional market incompleteness, the individual has a strong demand for savings to smooth out her consumption path.

The other interesting observation is that the impacts of forced unemployment risk and borrowing constraints are non-trivial, rather they are highly nonlinear depending on the levels of wealth at unemployment. Due to the concavity of logarithmic utility function, the unemployment-risk-induced savings motive becomes stronger with respect to changes of wealth for individuals with small wealth compared to those with large wealth. Since the forced unemployment event is distributed continuously following an exponential distribution with positive intensity $\delta$, such impacts are represented by two integrals over state variables between $\underline{\lambda}$ and $\bar{\lambda}$ leading to the unemployment-risk-induced savings in (22).

Optimal Consumption and Investment. Having explored how the individual accumulates her time- $t$ optimal wealth in the event of both forced unemployment and borrowing constraints, next, we characterize the optimal consumption and investment strategies analytically. 
Theorem 3.2 The optimal consumption $c^{*}$ and investment $\pi^{*}$ are derived in closed-form prior to voluntary retirement, i.e., for $0 \leq X(t)<\hat{x}$,

$$
\begin{aligned}
& c^{*}(t)=(\beta+\delta)\left[\left(X(t)+\frac{I_{1}}{r}\right)-B(\underline{\lambda}) \lambda(X(t))^{-\alpha_{\delta}}-B^{*}(\bar{\lambda}) \lambda(X(t))^{-\alpha_{\delta}^{*}}-U\right], \\
& \pi^{*}(t)=\frac{\theta}{\sigma}\left[\left(X(t)+\frac{I_{1}}{r}\right)+\right.\left(\alpha_{\delta}-1\right) B(\underline{\lambda}) \lambda(X(t))^{-\alpha_{\delta}}+\left(\alpha_{\delta}^{*}-1\right) B^{*}(\bar{\lambda}) \lambda(X(t))^{-\alpha_{\delta}^{*}} \\
&\left.-\frac{2 \delta}{\theta^{2} \beta} \ln \left(X(t)+\frac{I_{2}}{r}\right) c^{*}(t)-U+\alpha_{\delta} \times U 1+\alpha_{\delta}^{*} \times U 2\right],
\end{aligned}
$$

where $U$ is the unemployment-risk-induced savings defined in Theorem 3.1, U1 and U2 are its first and second terms, respectively, defined in Theorem 3.1.

Proof. See Proofs in the Online Appendix. Q.E.D.

Equation (23) explains the typical pattern of the individual's optimal consumption. We characterize four segments in the optimal consumption function. In the complete market setting without retirement, borrowing constraints, and forced unemployment risk, the PIH rule prevails. While in the incomplete market setting, the optimal decision is to reduce current consumption and build wealth for voluntary retirement, binding borrowing constraints, and/or high likelihood of forced unemployment.

Interesting economic insights into the optimal consumption result from the investigation of the marginal propensities to consume (MPC) out of financial wealth. The MPC formula 
is obtained in closed-form:

$$
\begin{aligned}
\frac{\partial c^{*}(t)}{\partial X(t)}= & (\beta+\delta) \\
& +(\beta+\delta) \frac{\partial \lambda(X(t))}{\partial X(t)}\left[\alpha_{\delta} B(\underline{\lambda}) \lambda(X(t))^{-\alpha_{\delta}}+\alpha_{\delta}^{*} B^{*}(\bar{\lambda}) \lambda(X(t))^{-\alpha_{\delta}^{*}}\right. \\
& -\frac{2 \delta}{\theta^{2} \beta} \ln \left(X(t)+\frac{I_{2}}{r}\right) c^{*}(t) \\
& +\alpha_{\delta} \times\{\text { first term of unemployment-risks-induced savings }\} \\
& \left.+\alpha_{\delta}^{*} \times\{\text { second term of unemployment-risks-induced savings }\}\right] c^{*}(t) .
\end{aligned}
$$

In terms of the MPC, it is possible to set a stable path of consumption profiles regardless of levels of wealth if we consider only the first $(\beta+\delta)$ term on the right-hand side of $(25)$. This is known as consumption smoothing.

Parker (1999) and Souleles (1999) suggest empirical estimates of MPC ranging from 0.2 to 0.6. Carroll (1992), however, suggests much lower values of MPC ranging from 0.04 to 0.07. We show that the MPC relies crucially on levels of wealth, supporting Carroll et al. (2015), and it can be larger or smaller due to the two-dimensional market incompleteness. Because of the following inequality

$$
\frac{\partial \lambda(X(t))}{\partial X(t)}<0
$$

the extra terms on the right-hand side of (25) induced by forced unemployment risk and borrowing constraints are found to increase the MPC. In particular, the term

$$
-\frac{2 \delta}{\theta^{2} \beta} \ln \left(X(t)+\frac{I_{2}}{r}\right) c^{*}(t)
$$

implies that the individual who is borrowing constrained needs to finance her consumption adjusted by her utility value of time- $t$ optimal wealth, in the event of forced unemploy- 
ment. Accordingly, the individual needs to accumulate extra wealth to sustain her future consumption, resulting in an increase in the MPC.

However, the last terms involving the first and second terms of unemployment-riskinduced savings turn out to affect the MPC negatively. We find that there is a trade-off between consuming instantly and the available financial resources that the individual can afford to reserve. Naturally, the individual needs to secure precautionary wealth and hence, is more inclined to cut back her consumption in the event of forced unemployment. Moreover, such a precautionary savings motive becomes stronger as wealth approaches zero because of borrowing constraints, leading to a decrease of the MPC.

Overall, the decision to consume more or less with respect to an increase of wealth falls, to a large extent, on how the individual reacts to the market incompleteness caused by forced unemployment risk and borrowing constraints.

As to the optimal investment, in addition to the standard CAPM mean-variance term (the first term on the right-hand side of (24)), the individual has a need to invest in the stock market according to retirement-induced, borrowing-constraints-induced, and unemployment-risk-induced savings motives, as would be characterized in time- $t$ optimal wealth (21). The individual invests more in the stock market by a fraction $\left(\alpha_{\delta}-1\right)$ of retirement-induced savings in light of the increased flexibility in choosing the optimal timing of retirement (Farhi and Panageas, 2007; Dybvig and Liu, 2010; Jang et al., 2013; BJP). However, if borrowing constraints are considered, the individual can also reduce her stock investment by the fraction $\left(\alpha_{\delta}^{*}-1\right)$ of borrowing-constraints-induced savings, resulting in reduced financial resources for stock investment (Dybvig and Liu, 2010; Jang et al., 2013). 
In line with the analysis of the MPC, the optimal choice is to satisfy one's current consumption needs, and hence, reduce stock investment. However, at the same time, the individual needs to balance between current and future consumption in the aftermath of forced unemployment, and thus, has a need to invest in the stock market.

Overall, we find two opposing effects: on the one hand, market incompleteness increases background risk, leading to precautionary savings motive that reduces stock investment (Kimball, 1993; Koo, 1998; Heaton and Lucas, 1997); on the other hand, it encourages a diversification motive that increases stock investment (Benzoni et al., 2007; Ahn et al., 2019). Hence, the optimal decision to increase or decrease investment in the stock market depends on one's financial wealth and investment opportunity, which we illustrate in the next section.

\section{Quantitative Analysis}

In this section, we carry out an in-depth quantitative analysis to illustrate various properties of the individual's optimal consumption, investment, and retirement strategies.

\subsection{Baseline Parameters}

Following BJP, the baseline parameter values are set as follows: the risk-free interest rate $r=3.71 \%,{ }^{30}$ the subjective discount rate $\beta=r,{ }^{31}$ the expected rate $\mu$ and standard

\footnotetext{
${ }^{30}$ The risk-free rate can be chosen by the annual rate of return from rolling over 1-month T-bills between 1926 and 2009. Source: Bureau of Labor Statistics.

${ }^{31}$ This is acceptable in terms of the perceived forced unemployment risk $\beta+\delta$ in the discount rate.
} 
deviation $\sigma$ of stock returns are $\mu=11.23 \%$ and $\sigma=19.54 \%,{ }^{32}$ the annual rate of labor income $I_{1}$ is normalized as one, the post-retirement income $I_{2}=0.10,{ }^{33}$ and the postretirement leisure preference $K=3$ (Dybvig an Liu, 2010).

In our study, retirement occurs in two cases. First, the individual optimally enters (voluntary) retirement when she approaches the endogenously determined wealth threshold for retirement. Second, the individual is forced to retire due to a forced unemployment shock. Here, we allow for a small possibility of the unemployment shock via a Poisson shock parameter $\delta$ that causes a down-jump of income from $I_{1}$ to $I_{2} \cdot{ }^{34}$ For the baseline parameter value, we choose a very small possibility of forced unemployment by setting $\delta=0.5 \%$. Our conservative choice for this parameter value has two practical interpretations. Similar to the Cocco et al. (2005) model in which a $0.5 \%$ annual probability of zero income has been matched up with a disastrous labor income shock, the individual, in our study, may be forced to be unemployed with a $0.5 \%$ probability. Second, the expected time to forced unemployment is 200 years by setting $\delta=0.5 \%$.

Our conservative choice of parameter $\delta$ works in real retirement situations because an unemployment shock considered in this paper is not equivalent to a temporary unemploy-

\footnotetext{
${ }^{32}$ We use the return and standard deviation of the world's large stocks between 1926 and 2009. For details, see pp. 170 of Bodie, Kane, and Marcus (2011).

${ }^{33}$ Following Lynch and Tan (2011), the post-retirement income can be financed by annuitized payout from a Social Security program or subsistence such as public welfare or unemployment allowances provided by the government.

${ }^{34}$ Carroll (1992) utilizes this type of disastrous labor income shock and Cocco et al. (2005) introduce the disastrous income shock with $0.5 \%$ probability of zero income at each period over the life cycle.
} 
ment situation, but to a forced retirement scenario, which is akin to a disability shock. According to Lachance and Seligman (2008), the most commonly cited reason for involuntary retirement is poor health conditions (43.6\%). Along these lines, we could match up the expected time to forced unemployment with the expected retirement age reported in Dwyer and Mitchell (1999). Based on years of survival in employment with poor health conditions, the unemployment intensity $\delta$ is $3.62 \%$ and $17.86 \%$ for people who are conditional on working at age 35 and 57, respectively. Comparatively, our choice of the baseline parameter value of $0.5 \%$ is, indeed, a conservative estimation.

\subsection{Optimal Consumption and Investment Strategies}

Forced unemployment risk negatively affects the optimal consumption and investment (Table 1). Even small chances of forced unemployment can significantly change one's optimal strategies. Given $\hat{x}$ is the endogenously determined threshold for voluntary retirement, ${ }^{35}$ the consumption of the individual with financial wealth $\hat{x}-45$ decreases substantially by $16.42 \%$ as $\delta$ increases from 0 to $0.5 \%$, which shows a significant discontinuity and a dramatic change in the concavity of consumption with small values of $\delta$. Further, consumption decreases as $\delta$ increases, demonstrating a strengthened precautionary savings motive (Carroll, 1992).

\section{[Insert Table 1 here.]}

Forced unemployment risk also influences the sensitivity of consumption with respect

\footnotetext{
${ }^{35}$ We also illustrate $\hat{x}$ in the next subsection.
} 
to changes in wealth. In the absence of forced unemployment risk (i.e., when $\delta=0$ ), the consumption increases by $31.58 \%$ as wealth increases from $\hat{x}-45$ to $\hat{x}-40$, whereas it increases by $11.94 \%$ as wealth increases from $\hat{x}-25$ to $\hat{x}-20$. In the presence of forced unemployment risk (when $\delta=0.5 \%$ ), the consumption increases by $40.05 \%$ as wealth increases from $\hat{x}-45$ to $\hat{x}-40$, whereas it increases by $12.86 \%$ as wealth increases from $\hat{x}-25$ to $\hat{x}-20$.

\section{[Insert Figure 1 here.]}

\section{[Insert Figure 2 here.]}

It creates two opposing effects on one's investment decision. The optimal decision relies on the interdependent relationship between wealth and investment opportunity. Given a constant investment opportunity, forced unemployment does not seem to have a significant impact on the sensitivity of investment to changes in wealth (Table 1). However, with a variation of investment opportunity, the sensitivity changes with one's wealth (Figures 1 and 2). In the presence of two-dimensional market incompleteness, investment in the stock market decreases (increases) with investment opportunity when wealth is low (high).

\subsection{Optimal Retirement Strategy}

Table 2 suggests that the borrowing-constrained individual with forced unemployment risk $(\delta>0)$ accepts a lower threshold of wealth for retirement than indicated by a complete market model $(\delta=0$; Farhi and Panageas, 2007; Dybvig and Liu, 2010; Jang et al., 2013). This implies that existing guidance on retirement without taking into account the 
two-dimensional market incompleteness (borrowing constraints and forced unemployment risk) represents an overly simplified situation. In this subsection, we develop quantitative measures associated with optimal retirement decisions to derive a more realistic wealth threshold under the market incompleteness.

\section{[Insert Table 2 here.]}

We measure the value of human capital by the marginal rate of substitution between income and financial wealth. It is the individual's subjective marginal value of labor income. The value of human capital plays a key role in determining the timing of optimal retirement. Intuitively, if the human capital value is higher than that of post-retirement income, it would induce the individual to continue to work. In contrast, a lower human capital value would encourage the individual to enter voluntary retirement to enjoy more leisure than work.

Definition 4.1 Let $\Phi\left(x ; I_{1}, \delta\right)$ be the value function described in Section 2.5 provided the annual rate of labor income prior $I_{1}$ and the forced unemployment intensity $\delta$. The value of human capital is

$$
\frac{\partial \Phi\left(x ; I_{1}, \delta\right)}{\partial I_{1}} / \frac{\partial \Phi\left(x ; I_{1}, \delta\right)}{\partial x}
$$

The value of human capital shows a hump-shaped pattern (Figure 3). It shows that labor income is highly appealing to individuals who are starting their full-time employment and hence, accumulating wealth. It gradually becomes less attractive as one's wealth approaches to a certain threshold (i.e., wealth for retirement). We can derive such a wealth 
threshold numerically. The intersection point of the human capital value and the present value of the actuarial fair value (PRAV) of post-retirement income represents the wealth for the retirement threshold. Comparing to the retirement threshold in the complete market, our two-dimensional incomplete market threshold is lower due to the reduced human capital value.

\section{[Insert Figure 3 here.]}

Further, the value of human capital decreases with investment opportunity when wealth is low, whereas it increases with investment opportunity when wealth is high (Figure 4). The rationale behind this is that the individual will not solely depend on risky labor income (with forced unemployment risk) to accumulate wealth when her wealth is low. Instead, it would be optimal for her to invest more in the stock market for diversification purposes rather than only resort to the risk-free investment.

\section{[Insert Figure 4 here.]}

Neglecting the two-dimensional market incompleteness can be costly to the borrowingconstrained individual who aims to attain her optimal retirement. We calculate the resulting utility costs of ignoring the market incompleteness by comparing two value functions with and without forced unemployment risk.

Definition $4.2 \Delta(x)$ is the certainty equivalent wealth gain (CEWG) with financial wealth $x$ if it satisfies

$$
\Phi\left(x-\Delta(x) ; I_{1}, \delta=0\right)=\Phi\left(x ; I_{1}, \delta>0\right),
$$


where $\Phi\left(x ; I_{1}, \delta\right)$ is the value function described in Section 2.5 provided the annual rate of labor income $I_{1}$ and the unemployment intensity $\delta$.

The utility costs increase as forced unemployment risk rises (Figure 5). The individual could lose up to $10 \%$ of her retirement wealth if she does not consider market incompleteness.

\section{[Insert Figure 5 here.]}

\subsection{Discussion on Unemployment Insurance}

We have, so far, shown that the two-dimensional market incompleteness caused by borrowing constraints and forced unemployment risk significantly affects an individual's optimal consumption, investment, and retirement strategies. In this subsection, we briefly discuss a possible unemployment insurance scheme, which can be considered as a pre-arranged financing instrument for the borrowing-constrained individual to respond to or recover from forced unemployment shocks.

In the case of insufficient social securities and limited private insurance market against large and negative wealth shocks, the role of insurance is of utmost importance to individuals in making life-cycle investment and savings decisions (Gormley et al., 2010). In this respect, Jang et al. (2013) have proposed a personalized unemployment insurance contract, through which borrowing-constrained individuals can hedge against their forced unemployment risk and derive optimal life-cycle strategies. ${ }^{36}$

\footnotetext{
${ }^{36}$ In Jang et al. (2013), the contract involves a stream of payments to an insurer in exchange for a
} 
Under our two-dimensional incomplete market framework, we can consider two opposing scenarios. On the one hand, the borrowing-constrained individual can adopt the insurance contract in the complete market as in Jang et al. (2013). On the other hand, she can still hedge her income shocks even if the unemployment insurance is not available, as outlined in our incomplete market framework. If we compare the value functions of the two opposing scenarios (with and without the insurance contract), we can calculate the fair value of the unemployment insurance, which represents a starting point towards designing such a new insurance contract. ${ }^{37}$

To obtain plausible indications on the fair value of the unemployment insurance, we use the Survey of Consumer Finances (SCF) data from 1995 to 2010. Specifically, we match up an individual's wealth-to-income ratios in our model with the ratios between family net worth and before-tax family income of the SCF. We group U.S. families into percentiles of net worth during the period (Figure 6). Both the family net worth and before-tax family income increase with the percentile of net worth.

\section{[Insert Figure 6 here.]}

The fair value of unemployment insurance decreases with individual's wealth. It shows that more-wealthy people pay less than less-wealthy people to obtain the insurance coverage (Table 3). The lower price of unemployment insurance for the wealthy reflects their ability to hedge against income shocks with large savings.

certain guaranteed level of wealth in the event of forced unemployment.

${ }^{37}$ The fair value can be regarded as the sum of subjectively discounted insurance premiums that individuals have to pay for the unemployment insurance. 


\section{[Insert Table 3 here.]}

The fair value of unemployment insurance also depends on individual's investment opportunities (summarized by expected return $\mu$ and volatility $\sigma$ ) and post-retirement leisure

preference $K$. The unemployment insurance becomes more expensive when investment opportunity decreases (with low $\mu$ or high $\sigma$ ) or leisure demand decreases (with low $K$ ), due to a high likelihood of unemployment at times of economic downturns. Also, the individual with low post-retirement leisure demand typically has high consumption needs via working longer rather than retiring earlier. Financing future consumption needs for a longer period can be more costly in the face of forced unemployment, resulting in an increase in the price of unemployment insurance.

\section{Conclusion}

We study an optimal retirement problem under the two-dimensional market incompleteness, caused by borrowing constraints and forced unemployment risk. We show that the two aspects jointly affect an individual's optimal consumption, investment, and retirement strategies. Our results suggest that neglecting the two-dimensional market incompleteness is costly to the borrowing-constrained individual who aims to attain her optimal retirement. Technically, our paper is also the first attempt to develop a new dynamic programming approach for solving an optimal retirement model in such a unique incomplete market setting.

We raise four questions that may be considered for future research on optimal retire- 
ment. First, the investment opportunity considered in this paper is assumed to be constant, i.e., risk-free interest rate, expected stock return, and stock volatility are all constants. Investigating the effects of a stochastic investment opportunity on the optimal retirement would be an interesting extension of the paper. One can consider a tractable way to model the stochastic investment opportunity through a continuous-time Markov regime-switching model.

Second, our voluntary retirement decision is controlled by the endogenously determined timing of optimal retirement. In addition to the retirement choice, one can allow for another labor supply flexibility by considering flexible working hours (Bodie et al., 1992). An optimal retirement model for an individual who can respond to forced unemployment risk by changing her working hours can be an interesting extension of the paper.

Third, we have not considered the positive general equilibrium implications of market incompleteness for our optimal retirement model. While with the help of Lucas-type equilibrium asset pricing framework, equity premium and risk-free interest rate can be significantly affected by voluntary retirement decisions under incomplete markets.

Finally, by introducing the possibility that an individual could re-enter the workforce after forced unemployment would improve the realism of the model. 


\section{References}

Angerer, X., P.-S. Lam. 2009. Income Risk and Portfolio Choice: An Empirical Study. Journal of Finance. 64 1037-1055.

Ahn, S., K. J. Choi, B. H. Lim. 2019. Optimal Consumption and Investment under TimeVarying Liquidity Constraints. Journal of Financial and Quantitative Analysis. forthcoming.

Bensoussan, A., B. G. Jang, S. Park. 2016. Unemployment Risks and Optimal Retirement in an Incomplete Market. Operations Research. 64 1015-1032.

Bensoussan, A., J. L. Lions. 1982. Application of Variational Inequalities in Stochastic Control. North Holland.

Benzoni, L., P. Collin-Dufresne, R. S. Goldstein. 2007. Portfolio Choice over the Life-Cycle when the Stock and Labor Markets Are Cointegrated. Journal of Finance. 62 2123-2167.

Bodie, Z., A. Kane, A. J. Marcus. 2011. Investments and Portfolio Management. McGrawHill, Ninth Edition.

Bodie, Z., R. C. Merton, W. F. Samuelson. 1992. Labor Supply Flexibility and Portfolio Choice in a Life Cycle Model. Journal of Economic Dynamics and Control. 16 427-449.

Campbell, J. Y. 1987. Does Saving Anticipate Declining Labor Income? An Alternative Test of the Permanent Income Hypothesis. Econometrica. 55 1249-1273. 
Carroll, C. D. 1992. The Buffer-Stock Theory of Saving: Some Macroeconomic Evidence. Brookings Papers on Economic Activity. 2 61-156.

Carroll, C. D., K. E. Dynan, S. D. Krane. 2003. Unemployment Risk and Precautionary Wealth: Evidence from Households' Balance Sheets. Review of Economics and Statistics. $85586-604$.

Carroll, C. D., J. Slacalek, K. Tokuoka, M. N. White. 2015. The Distribution of Wealth and the Marginal Propensity to Consume. Working Paper.

Cocco, J. F., F. J. Gomes, P. J. Maenhout. 2005. Consumption and Portfolio Choice over the Life Cycle. Review of Financial Studies. 18 491-533.

Cox, J. C., C. Huang. 1989. Optimal Consumption and Portfolio Policies when Asset Prices Follow a Diffusion Process. Journal of Economic Theory. 49 33-83.

Dwyer, D. S., O. S. Mitchell. 1999. Health Problems as Determinants of Retirement: Are Self-Rated Measures Endogenous? Journal of Health Economics. 18 173-193.

Dybvig, P. H., H. Liu. 2010. Lifetime Consumption and Investment: Retirement and Constrained Borrowing. Journal of Economic Theory. 145 885-907.

Dybvig, P. H., H. Liu. 2011. Verification Theorems for Models of Optimal Consumption and Investment with Retirement and Constrained Borrowing. Mathematics of Operations 
Research. 36 620-635.

Elmendorf, E., M. Kimball. 2000. Taxation of Labor Income and the Demand for Risky Assets. International Economic Review. 41 801-832.

Farhi, E., S. Panageas. 2007. Saving and Investing for Early Retirement: A Theoretical Analysis. Journal of Financial Economics. 83 87-121.

Frey, C. B., M. A. Osborne. 2017. The Future of Employment: How Susceptible are Jobs to Computerisation? Technological Forecasting and Social Change. 114 254-580. Friedman, M. 1957. A Theory of the Consumption Function. Princeton: Princeton University Press.

Gormley, T., H. Liu, G. Zhou. 2010. Limited Participation and Consumption-Saving Puzzles: A Simple Explanation and the Role of Insurance. Journal of Financial Economics. $96331-344$.

Heaton, J., D. Lucas. 1997. Market Frictions, Savings Behavior and Portfolio Choice. Macroeconomic Dynamics. 1 76-101.

Jang, B. G., S. Park, Y. Rhee. 2013. Optimal Retirement with Unemployment Risks. Journal of Banking and Finance. 37 3585-3604.

Karatzas, I., J. P. Lehoczky, S. E. Shreve, G.-L. Xu. 1991. Martingale and Duality Methods for Utility Maximization in an Incomplete Market. SIAM Journal of Control and 
Optimization. 29 702-730.

Karatzas, I., H. Wang. 2000. Utility Maximization with Discretionary Stopping. SIAM Journal on Control and Optimization. 39 306-329.

Kimball, M. S. 1993. Standard Risk Aversion. Econometrica. 61 589-611.

Koo, H. K. 1998. Consumption and Portfolio Selection with Labor Income: A Continuous Time Approach. Mathematical Finance. 8 49-65.

Lachance, M. E., J. S. Seligman. 2008. Involuntary Retirement: Prevalence, Causes, and Impacts. Working Paper.

Lynch, A. W., S. Tan. 2011. Labor Income Dynamics at Business-Cycle Frequencies: Implications for Portfolio Choice. Journal of Financial Economics. 101 333-359.

Merton, R. C. 1969. Lifetime Portfolio Selection under Uncertainty: The Continuous-Time Case. Review of Economics and Statistics. 51 247-257.

Merton, R. C. 1971. Optimum Consumption and Portfolio Rules in a Continuous-Time Model. Journal of Economic Theory. 3 373-413.

Munk, C., C. Sørensen. 2010. Dynamic Asset Allocation with Stochastic Income and Interest Rates. Journal of Financial Economics. 96 433-462.

Øksendal, B. 2007. Stochastic Differential Equations: An Introduction with Application. 
Fifth Edition. Springer, Berlin.

Parker, J. A. 1999. The Reaction of Household Consumption to Predictable Changes in Social Security Taxes. American Economic Review. 89 959-973.

Polkovnichenko, V. 2007. Life-Cycle Portfolio Choice with Additive Habit Formation Preferences and Uninsurable Labor Income Risk. Review of Financial Studies. 20 83-124.

Souleles, N. S. 1999. The Response of Household Consumption to Income Tax Refunds. American Economic Review. 89 947-958.

Viceira, L. M.. 2001. Optimal Portfolio Choice for Long-Horizon Investors with Nontradable Labor Income. Journal of Finance. 56 433-470.

Wang, C., N. Wang, J. Yang. 2016. Optimal Consumption and Savings with Stochastic Income and Recursive Utility. Journal of Economic Theory. 165 292-331. 


\begin{tabular}{c|cccccccccc}
\hline \hline$\delta \backslash x$ & $\hat{x}-45$ & $\hat{x}-40$ & $\hat{x}-35$ & $\hat{x}-30$ & $\hat{x}-25$ & $\hat{x}-20$ & $\hat{x}-15$ & $\hat{x}-10$ & $\hat{x}-5$ & $\hat{x}$ \\
\hline 0 & 0.5918 & 0.7787 & 0.9490 & 1.1103 & 1.2657 & 1.4168 & 1.5646 & 1.7097 & 1.8526 & 1.9936 \\
0.005 & 0.4946 & 0.6927 & 0.8681 & 1.0326 & 1.1903 & 1.3434 & 1.4927 & 1.6391 & 1.7831 & 1.9250 \\
0.006 & 0.4922 & 0.6901 & 0.8654 & 1.0299 & 1.1878 & 1.3408 & 1.4902 & 1.6367 & 1.7807 & 1.9227 \\
0.007 & 0.4899 & 0.6876 & 0.8628 & 1.0274 & 1.1853 & 1.3384 & 1.4879 & 1.6344 & 1.7785 & 1.9204 \\
\hline \hline 0 & 28.9932 & 43.4261 & 56.6174 & 69.2027 & 81.4303 & 93.4243 & 105.2557 & 116.9686 & 128.5927 & 140.1485 \\
0.005 & 22.0918 & 37.2083 & 50.6002 & 63.2734 & 75.5535 & 87.5893 & 99.4613 & 111.2181 & 122.8909 & 134.5011 \\
0.006 & 22.0244 & 37.0867 & 50.4454 & 63.0975 & 75.3645 & 87.3928 & 99.2619 & 111.0193 & 122.6957 & 134.3120 \\
0.007 & 21.9572 & 36.9664 & 50.2930 & 62.9247 & 75.1791 & 87.2004 & 99.0669 & 110.8252 & 122.5055 & 134.1282 \\
\hline \hline
\end{tabular}

Table 1: Optimal consumption (top table) and optimal risky investment (bottom table) as a function of initial wealth $x$ for several values of $\delta$. Default parameter values: $\beta=0.0371, r=0.0371$, $\mu=0.1123, \sigma=0.1954, I_{1}=1$, and $I_{2}=0.10$.

\begin{tabular}{c|ccc|ccc|cccc}
\hline \hline & \multicolumn{3}{|c|}{$\mu$} & \multicolumn{3}{|c|}{$\sigma$} & \multicolumn{4}{|c}{$K$} \\
$\delta$ & 0.1023 & 0.1123 & 0.1223 & 0.1854 & 0.1954 & 0.2054 & 2 & 3 & 4 \\
\hline 0 & 47.4590 & 51.1636 & 54.5313 & 52.5721 & 51.1636 & 49.8445 & 90.0721 & 51.1636 & 37.8977 \\
0.005 & 46.0740 & 49.7891 & 53.1892 & 51.2084 & 49.7891 & 48.4632 & 87.1063 & 49.7891 & 37.0099 \\
0.006 & 45.8201 & 49.5342 & 52.9377 & 50.9543 & 49.5342 & 48.2083 & 86.5632 & 49.5342 & 36.8440 \\
0.007 & 45.5731 & 49.2850 & 52.6911 & 50.7057 & 49.2850 & 47.9592 & 86.0340 & 49.2850 & 36.6814 \\
\hline \hline
\end{tabular}

Table 2: Critical wealth levels $\hat{x}$ for various parameter values of $\mu, \sigma, K$, and $\delta$. Default parameter values: $\beta=0.0371, r=0.0371, I_{1}=1$, and $I_{2}=0.10$. 


\begin{tabular}{ccccccccccc}
\hline \hline & \multicolumn{3}{c}{$\mu$} & \multicolumn{3}{c}{$\sigma$} & & & $\mathrm{K}$ & \\
\cline { 2 - 10 } Percentile of net worth & 0.1023 & 0.1123 & 0.1223 & 0.1854 & 0.1954 & 0.2054 & 2 & 3 & 4 \\
\hline $0-25$ & 0.7978 & 0.5942 & 0.4433 & 0.5279 & 0.5942 & 0.6617 & 0.6617 & 0.5942 & 0.4917 \\
$25-49.9$ & 0.2792 & 0.2105 & 0.1590 & 0.1878 & 0.2105 & 0.2334 & 0.2754 & 0.2105 & 0.1721 \\
$50-74.9$ & 0.1571 & 0.1201 & 0.0919 & 0.1077 & 0.1201 & 0.1325 & 0.1606 & 0.1201 & 0.0964 \\
$75-89.9$ & 0.0933 & 0.0723 & 0.0560 & 0.0652 & 0.0723 & 0.0794 & 0.1000 & 0.0723 & 0.0565 \\
$90-100$ & 0.0606 & 0.0476 & 0.0374 & 0.0431 & 0.0476 & 0.0520 & 0.0687 & 0.0476 & 0.0359 \\
\hline \hline
\end{tabular}

Table 3: Fair value of unemployment insurance as a percentage of individual wealth for various parameter values of $\mu, \sigma$, and $K$. Default parameter values: $\delta=0.005, \beta=0.0371$, $r=0.0371, I_{1}=1$, and $I_{2}=0.10$. 

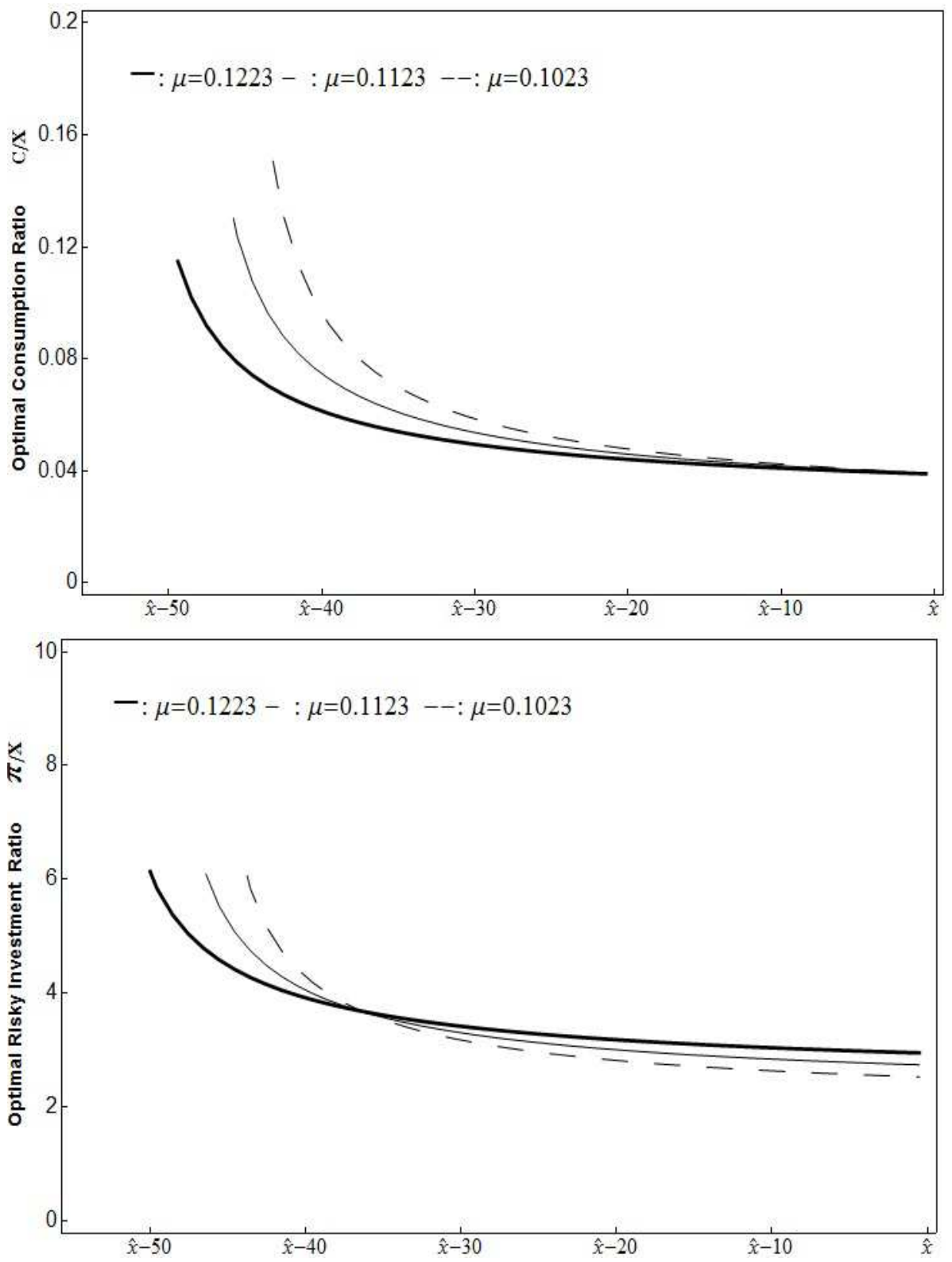

Figure 1: Optimal consumption to wealth ratio and risky investment to wealth ratio as a function of initial wealth $x$ for various expected rates $\mu$ of stock returns. Default parameter values: $\delta=0.005, \beta=0.0371, r=0.0371, \sigma=0.1954, K=3, I_{1}=1$, and $I_{2}=0.10$. 

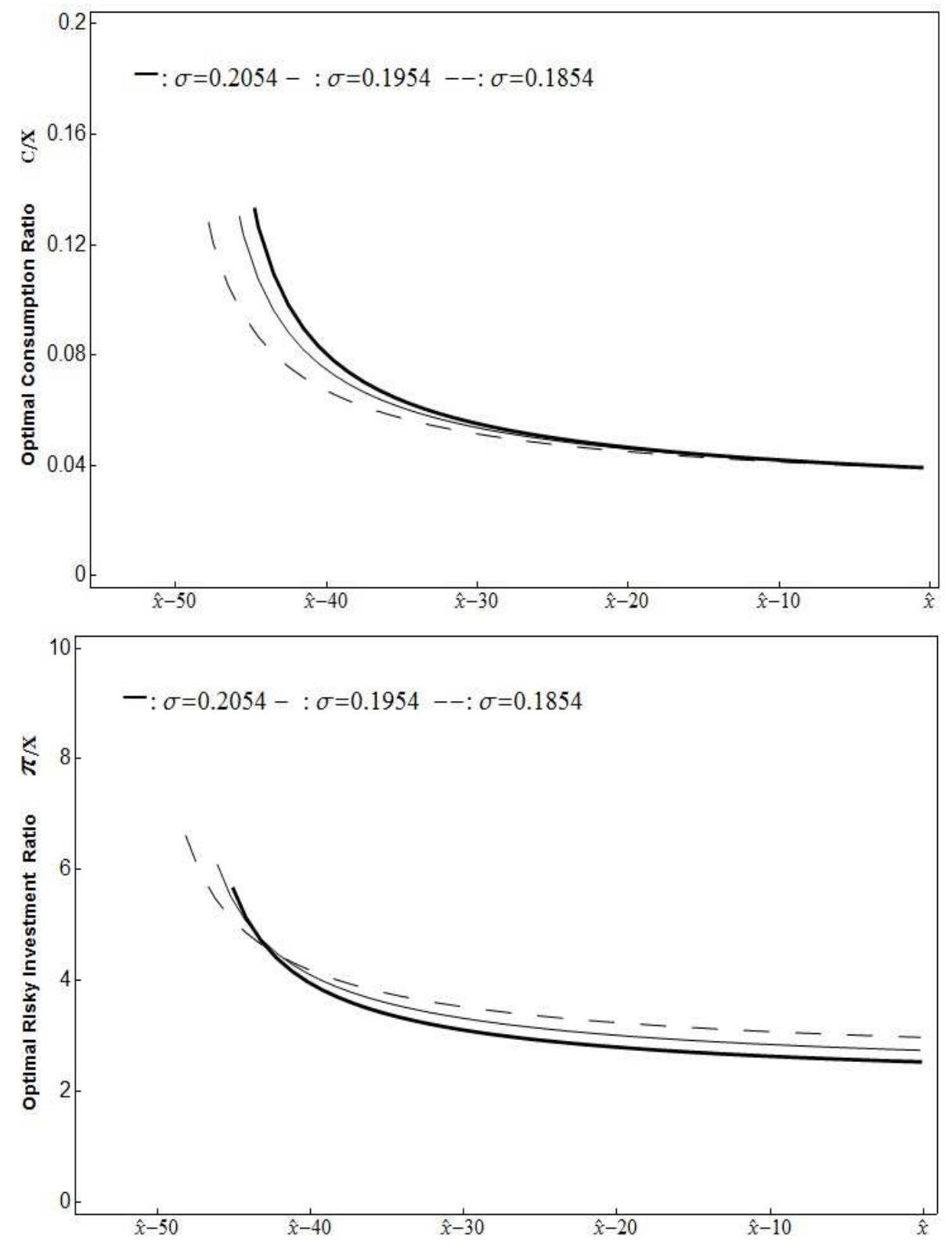

Figure 2: Optimal consumption to wealth ratio and risky investment to wealth ratio as a function of initial wealth $x$ for various stock volatilities $\sigma$.Default parameter values: $\delta=0.005$, $\beta=0.0371, r=0.0371, \mu=0.1123, K=3, I_{1}=1$, and $I_{2}=0.10$. 


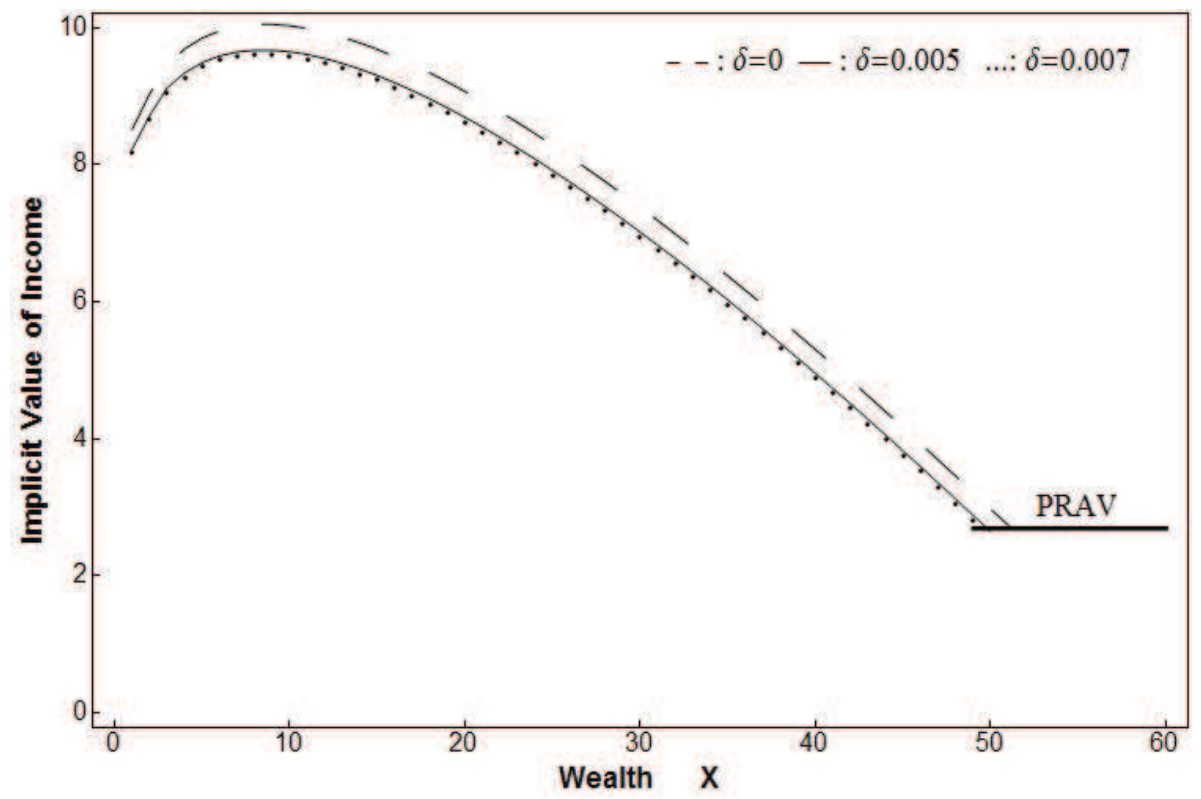

Figure 3: Value of human capital as a function of initial wealth $x$. Default parameter values: $\beta=0.0371, r=0.0371, \mu=0.1123, \sigma=0.1954, K=3, I_{1}=1$, and $I_{2}=0.10$. 

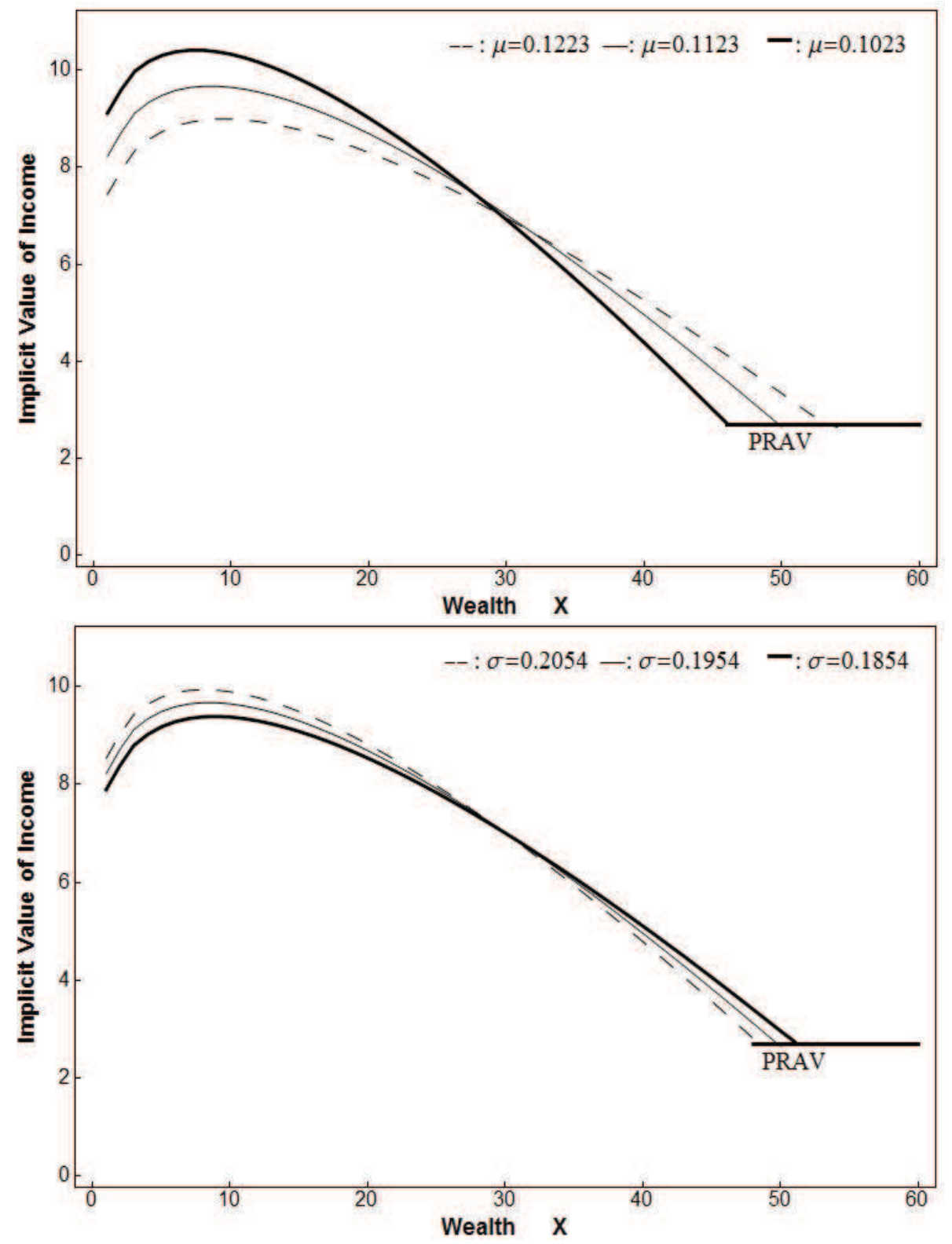

Figure 4: Value of human capital as a function of initial wealth $x$ for various parameter values of investment opportunity set $(\mu$ and $\sigma$ ). Default parameter values: $\delta=0.005, \beta=0.0371$, $r=0.0371, K=3, I_{1}=1$, and $I_{2}=0.10$. 


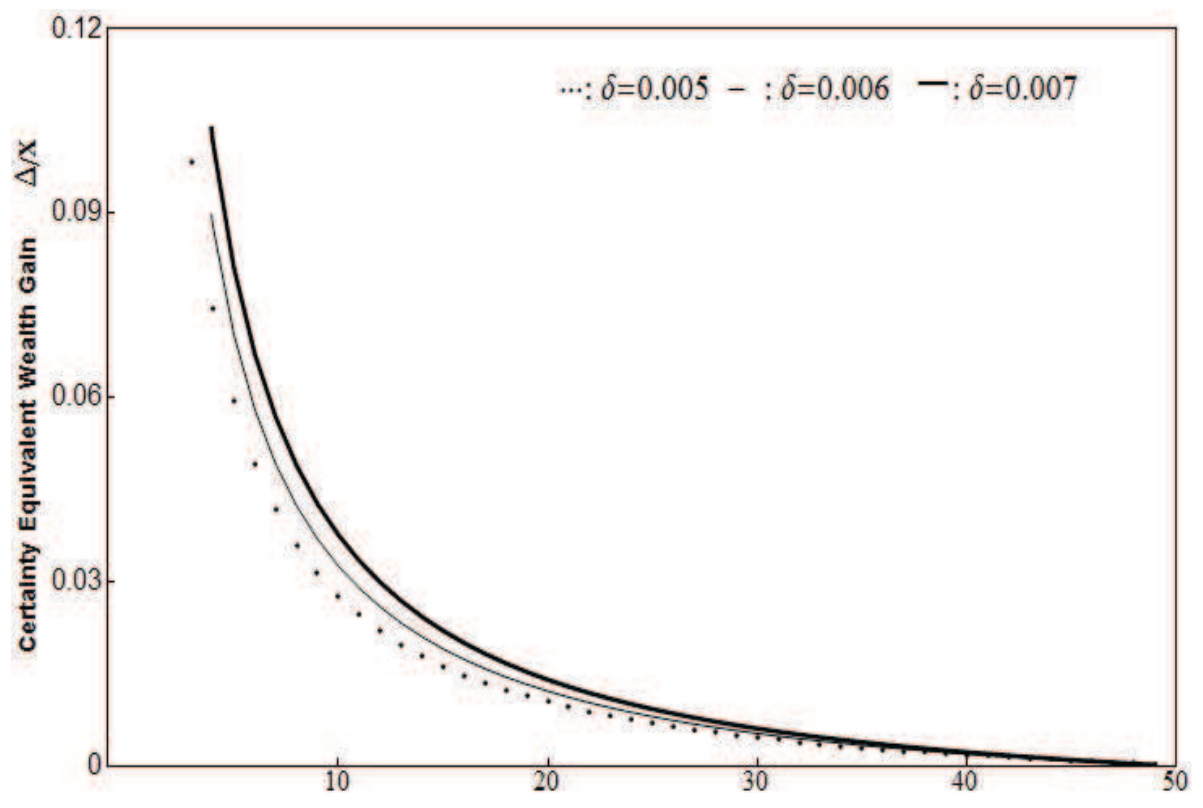

Figure 5: Certainty equivalent wealth gain (CEWG) to wealth ratio, $\Delta(x) / x$, for various values of unemployment intensities $\delta$. Default parameter values: $\beta=0.0371, r=0.0371, \mu=0.1123$, $\sigma=0.1954, I_{1}=1$, and $I_{2}=0.10$. 

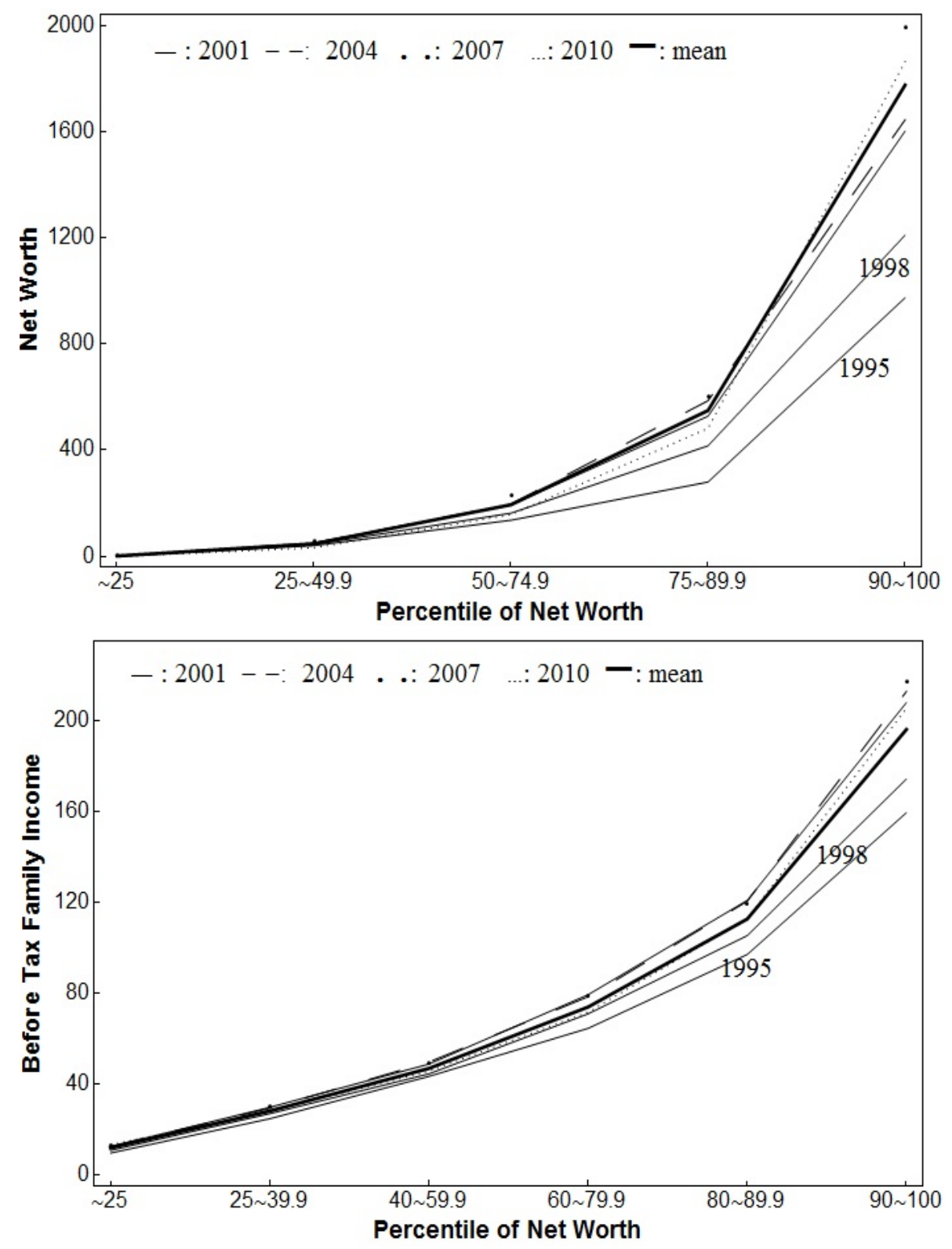

Figure 6: Family net worth and before-tax family income by percentile of net worth from the SCF for the period 1995-2010. 